Universidade de São Paulo

Instituto de Física

\title{
Interfaces Híbridas de Estireno sobre Silício
}

\author{
Francisco Nogueira Lima
}

Orientadora: Prof. Dra. Marília Junqueira Caldas

Dissertação apresentada ao Instituto de Física para a obtenção do título de Mestre em Ciências

\section{Comissão Examinadora:}

Profa. Dra. Marília Junqueira Caldas (IF-USP)

Prof. Dr. Sergio Luiz Morelhão (IF-USP)

Prof. Dr. Vitor Rafael Coluci (UNICAMP)

São Paulo 


\title{
FICHA CATALOGRÁFICA
}

Preparada pelo Serviço de Biblioteca e Informação do Instituto de Física da Universidade de São Paulo

\author{
Lima, Francisco Nogueira
}

Interfaces Híbridas de Estireno sobre Silício.

São Paulo, 2013

Mestrado (Dissertação) - Universidade de São Paulo. Instituto de Física. Depto. de Física dos Materiais e Mecânica.

Orientador: Profa. Dra. Marília Junqueira Caldas

Área de Concentração: Física da Matéria Condensada

Unitermos: 1. Física da Matéria Condensada; 2. Física do Estado Sólido; 3. Propriedades dos sólidos.

USP/IF/SBI-048/2011 

"Eu consigo calcular o movimento dos corpos celestiais, mas não a loucura das pessoas".

Isaac Newton 



\section{Agradecimentos}

- À minha família.

- À minha orientadora Marília Junqueira Caldas.

- À Regina Lélis de Sousa pelas inestimáveis contribuições a este trabalho, meus sinceros votos de admiração e respeito.

- Aos amigos do Grupo Nanomol, pelos momentos descontraídos e pelo bom ambiente acadêmico que tivemos.

- À secretária Sandra Regina que faz a vida acadêmica dos estudantes do Grupo Nanomol muito mais fácil. Obrigado por tudo.

- Ao CNPQ e à CAPES pelo suporte financeiro. 


\section{Resumo}

Este trabalho trata do estudo teórico atomístico das conformações da molécula de estireno sobre a superfície de $\operatorname{Si}(100)(2 x 1): H$. Estudamos a molécula fisissorvida e quimissorvida sobre esta superfície. Os cálculos foram realizados através de Dinâmica Molecular Clássica. Nós reparametrizamos o Universal Force Field (UFF) com base em cálculos ab initio para sistemas modelo, e comparação a dados experimentais. Nossos resultados indicam que no processo de fississorção a região de vale da superfície é preferencial, e ocorre formação de agregados de moléculas antes do contato com a superfície. Quando passamos à análise da quimissorção de uma molécula, a região de vale permanece sendo o sítio preferencial para a posição do grupo vinil. Para as conformações de linhas de estireno, a estrutura mais estável tem todas as moléculas dispostas sobre a região de vale (ordenamento tipo "pilha- $\pi$ "); identificamos também outra estrutura, quase degenerada em energia, na qual o grupo vinileno se dispõe em conformação tipo "espinha de peixe", alternando entre a região de vale e sobre o dímero. 


\section{Abstract}

In this work we present a theoretical study of the conformation of styrene molecules on the $\operatorname{Si}(100)(2 x 1): H$ surface. We studied the conformations for styrene molecules physisorbed and chemisorbed on this surface. The study was conducted by Classical Molecular Dynamics. We performed a re-parametrization of the Universal Force Field (UFF), based on ab initio calculations for model structures, and comparison to experimental data. Our results show that for the physisorbed situations, the styrene molecules preferentially interact with the surface valley. We also identified that the molecules aggregate in clusters before reaching the surface. The valley is again the region of lowest energy for the vinylene position, for chemisorption of a single styrene molecule on the monohydride surface. For systems where we have a styrene layer chemisorbed on the dimer row, the most stable structure has all the molecules arranged on the valley region of the surface $(\pi$-stack); we find another structure, almost degenerate in energy, in which molecules arrange in a herringbone-like configuration, with the vinylene group alternating between the valley and dimer regions. 


\section{Conteúdo}

Resumo ii

Abstract iii

1 Introdução 1

2 Métodos Teóricos $\quad 8$

2.1 Dinâmica Molecular Clássica (DMC) . . . . . . . . . . . . . . 8

2.1.1 Campo de Forças Universal (Universal Force Field - UFF) . . 10

2.1.2 Módulo de Compressibilidade (Bulk Modulus - B) . . . . . . . 13

2.2 Metodologia Quântica . . . . . . . . . . . . . . . . . . . . 14

2.2.1 Teoria do Funcional da Densidade - DFT . . . . . . . . . . . 15

2.2.2 Equações de Kohn-Sham . . . . . . . . . . . . . . . . . . . . . 16

2.2.3 Aproximações para Troca e Correlação . . . . . . . . . . . . . 17

2.2.4 Cargas de Hirshfeld . . . . . . . . . . . . . . . . . . . . 18

2.2.5 Interação de van der Waals . . . . . . . . . . . . . . . . . . 19

2.3 Métodos DFT . . . . . . . . . . . . . . . . . . 21

2.3.1 Código ESPRESSO e Base de Ondas Planas . . . . . . . . . . 21

2.3.2 Código ESPRESSO e Pseudopotenciais . . . . . . . . . . . . . 22

2.3.3 Código FHI-AIMS e Bases Locais . . . . . . . . . . . . . . . 23

3 Reparametrização do UFF 25

3.1 Cálculos de Primeiros Princípios . . . . . . . . . . . . . . . . . 25 
3.2 Reparametrização das Interações Ligadas . . . . . . . . . . . . . 29

3.3 Reparametrização das Interações de Coulomb e Lennard-Jones . . . . 31

3.3 .1 Molécula Isolada . . . . . . . . . . . . . . . . . . . . 33

3.3.2 Superfícies de Si Hidrogenadas . . . . . . . . . . . . . . . 34

3.4 Reflexos nas Propriedades Eletrônicas . . . . . . . . . . . . . . . 47

4 Estudo de monocamadas de estireno sobre $\operatorname{Si}(100)(2 \times 1): H \quad 51$

4.1 Moléculas de Estireno Fisissorvidas . . . . . . . . . . . . . . . . 51

4.2 Moléculas de Estireno Quimissorvidas . . . . . . . . . . . 56

$\begin{array}{lll}5 & \text { Sumário e Conclusões } & 67\end{array}$

$\begin{array}{ll}\text { Referências Bibliográficas } & 69\end{array}$ 


\section{Capítulo 1}

\section{Introdução}

O silício, semicondutor estudado neste trabalho, é utilizado em grande número de aplicações tecnológicas, sendo a base da indústria atual de microeletrônicos. Cristaliza em estrutura tipo diamante, formando quatro ligações híbridas do tipo $\mathrm{sp}^{3}$ (Figura 1.1). Experimentalmente, o parâmetro de rede da célula unitária é 5,431 $\AA$ e os átomos vizinhos distam $2,35 \AA[1]$.

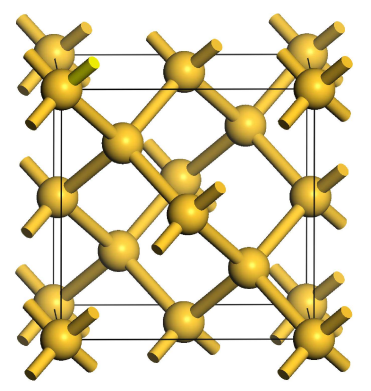

Figura 1.1: Estrutura cristalina do silício.

O "corte" do cristal para a formação de uma superfície em um material onde os átomos estão ligados covalentemente implica na ruptura dessas ligações. No caso do semicondutor sp3 teremos, dependendo da direção do corte, ao menos uma ligação quebrada, e o orbital remanescente, não saturado, na superfície é conhecido como "ligação flutuante" ou dangling bond. A presença da dangling bond torna a conformação estrutural instável e os átomos de superfície se acomodam em outra 
configuração de menor energia (dizemos que a superfície "relaxa"); em alguns casos, passa por um processo conhecido como reconstrução [2]. Ao "cortar" o cristal criando a superfície de silício $\mathrm{Si}(100)$, cada átomo de superfície passa a ter duas dangling bonds e, devido à instabilidade energética do sistema, a superfície é reconstruída com ligação entre dois átomos da superfície (que não estariam diretamente ligados no cristal), formando o que chamamos de dímero e que apresenta uma distorção estrutural. Um dos átomos do dímero é carregado negativamente (denominado up) e é repelido para fora da superfície, enquanto o outro átomo do dímero, carregado positivamente (denominado down) é atraído em direção à superfície. Formam-se então dímeros assimétricos (Figura 1.2). A transferência de cargas é responsável pela assimetria entre os átomos de Si up e down, como previsto teoricamente [2,3] e comprovado experimentalmente [4,5], principalmente por microscopia de tunelamento (STM - Scanning Tunneling Microscopy). Os dímeros assimétricos, também conhecidos como tilted, não são descritos classicamente, sendo esta assimetria um efeito puramante quântico [2].

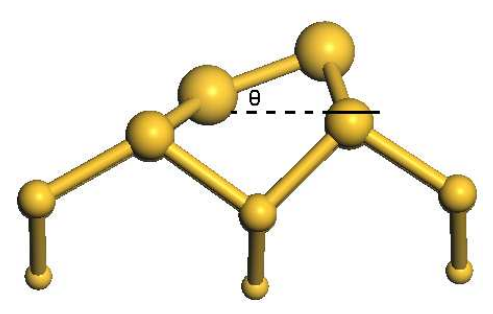

Figura 1.2: Reconstrução da superfície $\operatorname{Si}(100)(2 x 1)$ em dímeros assimétricos.

As consequências desta deformação afetam as propriedades estruturais, e as propriedades eletrônicas da superfície. Cálculos ab initio [3] demonstram que a formacão de dímeros simétricos fariam com que a superfície $\mathrm{Si}(100)$ ao ser reconstruída fosse metálica, enquanto dímeros assimétricos conduzem a um sistema semicondutor. A presença de uma ligação não saturada em um dos silícios do dímero leva os níveis de energia situados nos Si up e down localizarem-se no gap. Resultados experimentais de medidas de difração de elétrons de baixa energia (LEED - Low Energy Electron 
Diffraction) [2] fornecem a distância de ligação Si-Si entre 2,20 e 2,47 A, e uma inclinação do dímero com ângulo $\theta$ (Figura 1.2) entre 15 e $20^{\circ}$.

Imagens de STM obtidas à temperatura ambiente mostram a reconstrução $(2 \mathrm{x} 1)$ com dímeros simétricos, enquanto experimentos de LEED sugerem um modelo de dímeros assimétricos, porém com comportamento dinâmico a 300K [6]. Esta aparente contradição entre medidas de difração e as imagens de STM deve-se ao fato de não haver resolução do movimento de oscilação dos átomos de superfície entre as posições up e down [7].

Em experimentos de correntes de tunelamento a baixas temperaturas, quando o movimento de oscilação não está termicamente ativado, dímeros assimétricos [4] são observados e ficam ordenados em uma estrutura denominada c(4x2) (Figura 1.3), em um arranjo antiparalelo tipo zig-zag [4,7-9]. Quando a fileira de dímeros na esquerda mostra um átomo de silício negativamente carregado próximo à região de vale, o arranjo também se verifica para a fileira de dímeros imediatamente adjacente, posicionada à direita. Existem experimentos [10,11] que tratam da existência de

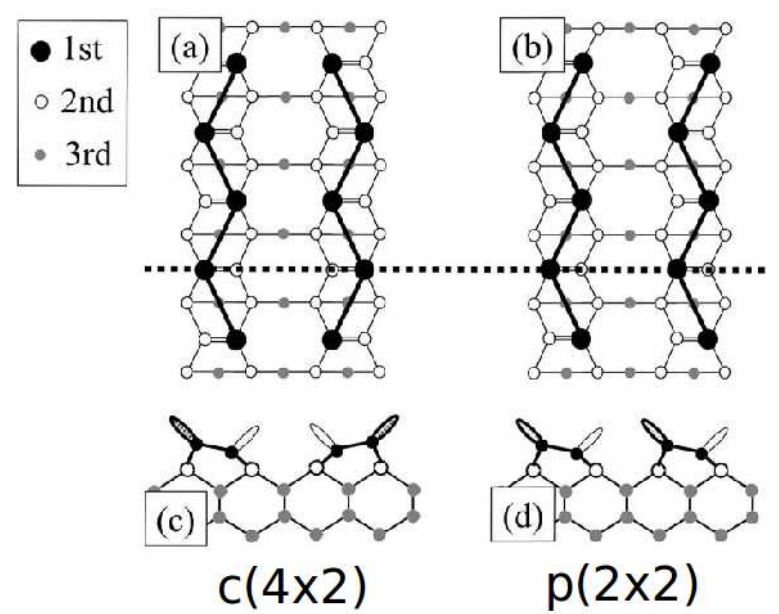

Figura 1.3: Vista de cima ((a) e (b)) e lateral ((c) e (d)) das reconstruções $\operatorname{Si}(100) c(4 \times 2)$ e Si(100)p(2x2). Figura retirada da referência [10].

outra possível reconstrução para a superfície limpa em baixas temperaturas, em uma reconstrução conhecida como $\mathrm{p}(2 \times 2)$ (Figura 1.3), com arranjo tipo zig-zag, 
mas paralelo. Para esta reconstrução, quando uma fileira de dímeros tem um átomo de Si down na região de vale, a fileira adjacente terá um átomo Si up. Características que permitem o reconhecimento de cada uma das reconstruções estão ilustradas na Figura 1.3 (retirada da referência [10]). Resultados de microscopia de força atômica em baixas temperaturas (aproximadamente $5 \mathrm{~K})$ mostram a fase $\mathrm{c}(4 \mathrm{x} 2)$ sempre dominante nas amostras [10]. A temperaturas mais altas, o arranjo de dímeros assimétricos torna-se aleatório devido à oscilação térmica [6].

A superfície $\mathrm{Si}(2 \mathrm{x} 1)$ limpa é muito reativa e ao ser retirada do vácuo é facilmente contaminada. O processo de contaminação causa alteração em suas propriedades físicas e químicas, o que limita suas aplicações tecnológicas. A passivação da superfície $\operatorname{Si}(2 \times 1)$ por absorção de hidrogênio dá origem à superfície $\operatorname{Si}(2 \times 1): H$. Esta superfície apresenta baixa reatividade, permitindo manipulação fora do vácuo e possibilitando assim um maior número de aplicações, principalmente em áreas onde o contato com o ambiente seja necessário.

A estrutura atômica da superfície hidrogenada é bem distinta da superfície não hidrogenada. Experimentos de espectroscopia no infravermelho (FTIR - Fourier Transform InfraRed) são bastante utilizados na verificação da homogeneidade destes sistemas, em função da presença de um sinal nítido da vibração $\mathrm{Si}-\mathrm{H}$ a aproximadamente $2100 \mathrm{~cm}^{-1}$. Devido ao aparecimento de técnicas bem sucedidas para a obtenção de superfícies $\operatorname{Si}(100): H$, teoria e experimento evoluiram em paralelo [12], possibilitando avanço considerável na compreensão dos processos de reconstrução induzidos pelo hidrogênio na superfície não hidrogenada. Atualmente sabemos de três fases hidrogenadas distintas, $(2 \mathrm{x} 1): \mathrm{H},(1 \mathrm{x} 1): 2 \mathrm{H}$ e $(3 \mathrm{x} 1): \mathrm{H}$ que podem ser obtidas dependendo das condições experimentais de hidrogenação (Figura 1.4).

Métodos químicos e técnicas em ultra alto vácuo ( $U H V$ - Ultra-High Vacuum) são formas bastante utilizadas na passivação das superfícies Si(100). A distinção entre as três reconstruções deve-se à quantidade de hidrogênios adsorvidos no dímero. A superfície $\mathrm{Si}(100)(2 \mathrm{x} 1)$ :H (Figura 1.4 (a)), também conhecida como "monohidrogenada", possui um padrão com fileiras de dímeros, separadas por uma região de 


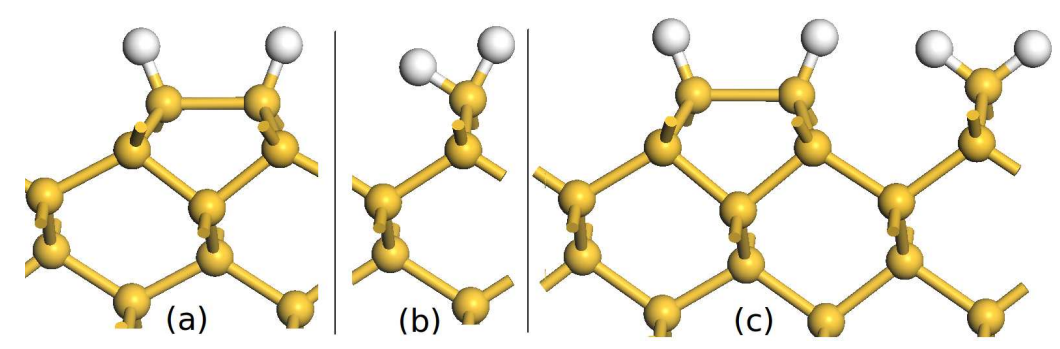

Figura 1.4: Vista lateral das superfícies (a) $\operatorname{Si}(100)(2 \mathrm{x} 1): \mathrm{H}$, (b) $\operatorname{Si}(100)(1 \mathrm{x} 1): 2 \mathrm{H}$ e (c) $\mathrm{Si}(100)(3 \mathrm{x} 1): H$. Os átomos mais escuros denotam os silícios e os brancos os hidrogênios.

vale que se assemelha à superfície $\operatorname{Si}(100)(2 \times 1)$. Neste caso, como não existem mais dangling bonds, os dímeros são simétricos. A superfície Si(100)(1x1):2H (Figura 1.4 (b)) não mais apresenta dímeros, sendo formada por grupos $\mathrm{H}-\mathrm{Si}-\mathrm{H}$, e é frequentemente denominada di-hidrogenada. A reconstrução Si(100)(3x1):H (Figura 1.4 (c)) é formada pela alternância das unidades $\mathrm{H}-\mathrm{Si}-\mathrm{Si}-\mathrm{H}$ e $\mathrm{H}-\mathrm{Si}-\mathrm{H}$.

Uma vertente promissora em eletrônica molecular está relacionada ao aproveitamento da tecnologia de semicondutores convencionais, dotando as superfícies desses materiais de novas funcionalidades vindas do acoplamento a materiais orgânicos. Em particular, monocamadas auto-montadas sobre silício são objeto de investigações recentes [13-16]. Já entre os materiais orgânicos, temos a escolha desde polímeros de cadeias muito longas a moléculas pequenas como o estireno que estudaremos aqui.

O grupo vinil da molécula de estireno, conhecido como alquênico mostra uma terminação bastante interessante para reação com substratos semicondutores pela possibilidade de abertura da ligacão dupla, propiciando uma ligação covalente direta (Si-C). O grupo da cabeça (fenil) é também muito interessante por liderar a família dos orgânicos conjugados, o que nos leva a imaginar várias maneiras de organizá-lo de forma a obter deslocalização eletrônica relevante [17-19]. O anel aromático é conhecido por sua estabilidade, o que sugere o estireno como um bom candidato para uma reação em cadeia através do grupo vinil [17]. De fato, a montagem de estireno sobre silício promete levar a uma nanoestrutura híbrida interessante como 
capeamento do inorgânico para posterior montagem de outras camadas orgânicas [20].

A funcionalização de superfícies de silício com materiais orgânicos tem sido uma área de pesquisa bastante ativa devido à possibilidade de novas aplicações. O desafio

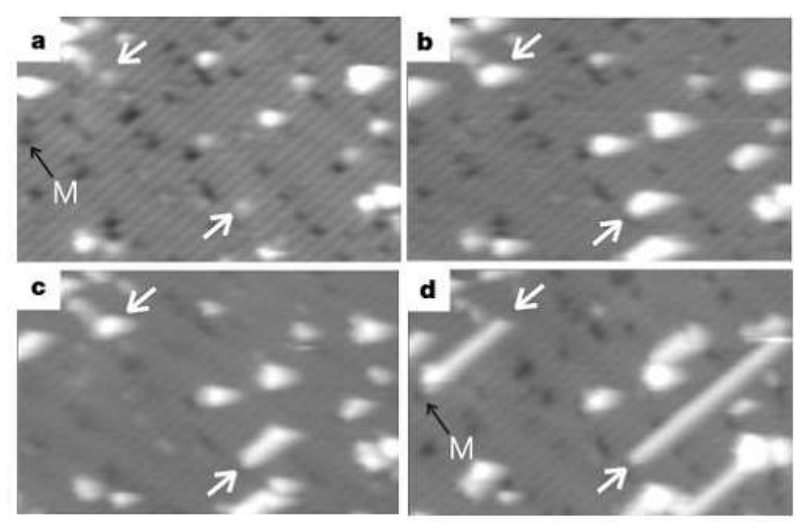

Figura 1.5: Crescimento de linhas de estireno sobre a $\mathrm{Si}(100)(2 \mathrm{x} 1): \mathrm{H}$ com diferentes concentracões diluídas de dangling bonds de Si. Na figura, temos uma sequência de imagens de STM correspondendo a um aumento de exposição ao estireno: (a) 3 L; (b) $28 \mathrm{~L}$; (c) $50 \mathrm{~L}$; (d) $105 \mathrm{~L}$. As linhas brancas denotam dois sítios de dangling bonds que levam ao crescimento de longas linhas de estireno. O defeito (M) marcado na figura, marca onde termina o crescimento da monocamada. Reproduzido da Figura 2 da referência Wolkow et al [17].

é produzir monocamadas finas e ordenadas e nesta direção precisamos compreender a morfologia destes sistemas muito complexos. Recentemente, a possibilidade de automontagem de moléculas de estireno sobre a $\mathrm{Si}(100)(2 \mathrm{x} 1): \mathrm{H}$ (Figura 1.5) foi demonstrado por Wolkov e Lopinski [17], porém muito pouco se sabe sobre estas nanoestruturas. Nota-se na figura a aparente ordem da montagem em fileiras, o que é bastante promissor para nano-modelagem sobre a superfície.

O aparecimento de linhas de estireno sobre a $\mathrm{Si}(100)(2 \mathrm{x} 1): \mathrm{H}$ é consistente com o mecânismo de reação em cadeia ilustrado na Figura 1.6. Utilizando a ponta do STM, cria-se uma primeira dangling bond na superfície através da retirada de 


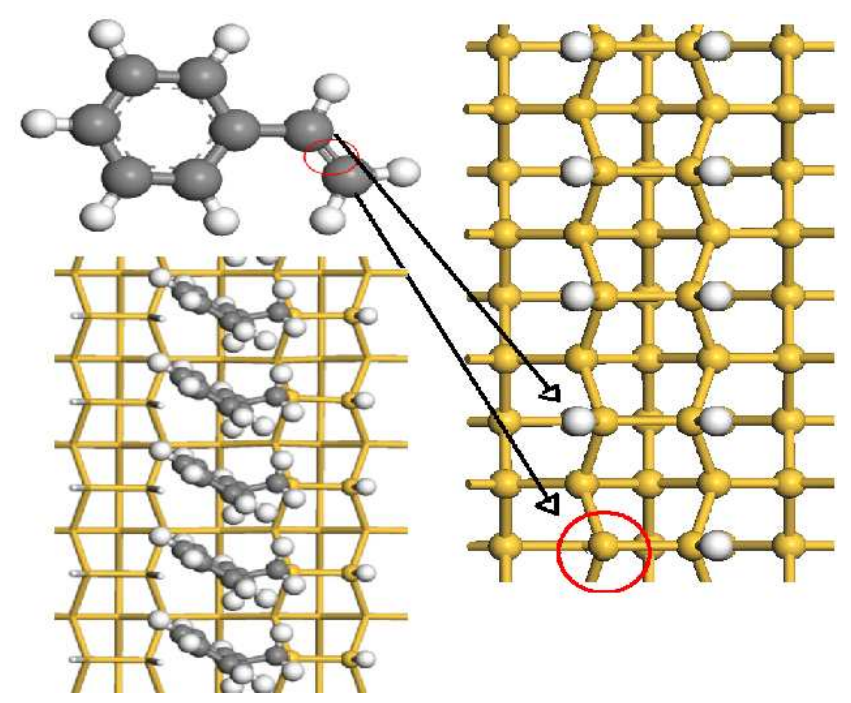

Figura 1.6: Mecânismo de reação em cadeia para formação de linhas de estireno sobre a $\operatorname{Si}(100)(2 \times 1): H$. Os círculos mostrados na figura indicam a ligação dupla da terminação vinil da molécula e um primeiro sítio de dangling bond sobre a superfície.

um hidrogênio do dímero de Si (círculo sobre a superfície). O estireno reage com a dangling bond pela abertura da ligação dupla da terminação vinil da molécula, formando-se uma ligação $\mathrm{Si}-\mathrm{C}$ entre o carbono da extremidade do vinil e o silício não hidrogenado de superfície. O carbono adjacente ao da ligação $\mathrm{Si}-\mathrm{C}$ agora tem uma ligação pendente, e para completar suas ligações "rouba" o hidrogênio do dímero de Si vizinho, criando uma dangling bond. Após chegada de mais uma molécula sobre a superfície o processo de reação é reiniciado, e as linhas são formadas por automontagem.

A análise através de STM, entretanto, não permite investigar mais em detalhe, na visão atomística, a ordem aparente das linhas: se as moléculas estão emparelhadas com anéis fenil em paralelo ou outra geometria interna menos favorável à condução eletrônica. Neste trabalho focalizamos a viabilidade de estudar estas estruturas através de Dinâmica Molécular Clássica, e analisar se existe uma ordem de estabilidade intrínseca entre diferentes ordenamentos inter-moleculares. 


\section{Capítulo 2}

\section{Métodos Teóricos}

Neste trabalho utilizamos métodos de simulação de propriedades estruturais e eletrônicas de superfícies híbridas orgânico-inorgânico. Para o estudo da estabilidade de linhas montadas de estireno sobre a $\mathrm{Si}(100)(2 \mathrm{x} 1): \mathrm{H}$ devemos tratar uma grande quantidade de átomos e configurações possíveis. Cálculos de primeiros princípios são utilizáveis apenas para sistemas-modelo e o uso de métodos clássicos empíricos torna-se importante. Neste capítulo, descrevemos brevemente pontos relevantes dos métodos de Dinâmica Molecular Clássica e Teoria do Funcional da Densidade aqui utilizados [21,22].

\subsection{Dinâmica Molecular Clássica (DMC)}

A principal vantagem deste método está na possibilidade de estudar a evolução temporal de sistemas poliatômicos com grande número de átomos, a baixo custo computacional, com base em parâmetros empíricos derivados de cálculos ab initio ou dados.

As equações diferenciais de movimento podem ser integradas por meio de diferentes algoritmos matemáticos, aqui escolhemos o de Verlet [23] (equações 2.1 e 2.2). A cada ciclo temos a evolução do sistema do instante $t$ para $t+\delta t$, o que nos permite obter uma sequência de valores para as posições e velocidades de cada 
átomo, a partir de seus valores fornecidos num instante inicial:

$$
\begin{aligned}
& \vec{v}_{i}(t+\delta t)=\vec{v}_{i}(t)+\frac{1}{2}\left[\vec{a}_{i}(t+\delta t)+\vec{a}_{i}(t)\right] \delta t \\
& \vec{r}_{i}(t+\delta t)=\vec{r}_{i}(t)+\vec{v}_{i}(t) \delta t+\frac{1}{2} \vec{a}_{i} \delta t^{2}
\end{aligned}
$$

em que $\vec{r}_{i}(t)$ é a posição do i-ésimo átomo no instante $t$, e $\vec{v}_{i}(t)$ sua velocidade. A aceleração no instante $t, \vec{a}_{i}(t)$, fica definida pela equação de movimento 2.3 , onde $\vec{F}_{i}$ é a força resultante sobre o átomo $i$ devido às forças $\vec{F}_{i j}$ de interação com os demais átomos do sistema:

$$
\vec{a}_{i}(t)=\frac{1}{m_{i}} \vec{F}_{i}=\frac{1}{m_{i}} \sum_{j \neq i} \vec{F}_{i j} .
$$

A força sobre o átomo $i$ é obtida através da equação 2.4

$$
\vec{F}_{i}=-\nabla_{i} U
$$

onde $U$ é um conjunto de potenciais construídos para modelar interações ligadas e não ligadas entre os átomos. Os potenciais são escolhidos e parametrizados de forma a reproduzir características conhecidas dos sistemas como geometria, módulo de compressibilidade (bulk modulus) e outras propriedades de interesse. O conjunto de potenciais escolhidos para simulação dos sistemas definem o que chamamos "campos de força". Um campo de força bastante utilizado é o Universal Force Field (UFF) descrito na próxima seção.

A energia cinética, $E_{c}(t)$, de um sistema de $N$ átomos é definida a partir de suas velocidades, $\vec{v}_{i}(t)$

$$
E_{c}(t)=\sum_{i=1}^{N} \frac{m_{i}\left|\vec{v}_{i}(t)\right|^{2}}{2} .
$$

Pelo teorema de equipartição de energia a temperatura média do sistema, $\langle T\rangle$, fica definida pela relação

$$
\left\langle E_{c}\right\rangle=\frac{3 N}{2} k_{B}\langle T\rangle
$$


em que $\left\langle E_{c}\right\rangle$ é a energia cinética média do sistema definida em um período $\tau$ inicialmente definido.

Nas simulações de DMC as propriedades estruturais, energéticas e dinâmicas do sistema são calculadas a partir de suas médias sobre um conjunto de pontos do espaço de fase associado a um estado termodinâmico particular, caracterizado por um ensemble estatístico. Utilizamos em nossas simulações ora o Ensemble Canônico, onde as variáveis $T, V$ e $N$ (temperatura, volume e número de partículas) são mantidas constantes, ora o Ensemble Microcanônico, onde as variáveis $E, V$ e $N$ (energia, volume e número de partículas) são mantidas constantes. Estes ensembles estão presentes no módulo de simulação do pacote computacional Cerius $^{2}$ [24] que utilizamos para todos os cálculos de DMC e também para obtenção de estruturas de mínima energia a temperatura nula. O pacote Cerius ${ }^{2}$ inclui diversos campos de força para descrição das propriedades estruturais de cristais e moléculas.

\subsubsection{Campo de Forças Universal (Universal Force Field - UFF)}

Nesta seção faremos uma breve descrição do campo de força UFF, que possibilita a edição de parâmetros pelo usuário (campo "aberto"). De fato, aqui reparametrizamos o UFF, como será descrito em detalhes no capítulo 3. Além do UFF, utilizamos também o Polymer Consistent Force Field (PCFF) [25] disponibilizado no Cerius ${ }^{2}$, mas não editável, para comparação com nossos resultados.

O UFF foi proposto por Rappé e colaboradores em 1992 [26], sendo fundamentado em regras gerais, baseadas somente no elemento, em sua hibridização e na conectividade. O campo oferece um procedimento para se obter a parametrização de todos os elementos da tabela periódica.

A expressão para energia total no UFF, equação 2.7, é dada pela soma de termos de energia associados às interações entre átomos ligados, a saber comprimentos de ligação, ângulos simples, ângulos de inversão e torção; e termos relacionados a 
átomos não-ligados, neste caso energia eletrostática e de van der Waals.

$$
E_{T}=E_{R}+E_{\theta}+E_{\varphi}+E_{\omega}+E_{L J}+E_{e l}
$$

O termo $E_{R}$ pode ser escrito numa aproximação harmônica como:

$$
E_{R}=\frac{1}{2} K_{I J}\left(r_{I J}-r_{0}\right)^{2}
$$

sendo chamado de energia de estiramento entre dois átomos ligados $I$ e $J$. Os parâmetros $K_{I J}$ e $r_{0}$ representam a constante de força e comprimento de equilíbrio, respectivamente. $E_{R}$ também pode ser modelado por uma expressão quártica como:

$$
E_{R}=k_{2}\left(r-r_{0}\right)^{2}+k_{3}\left(r-r_{0}\right)^{3}+k_{4}\left(r-r_{0}\right)^{4}
$$

A expressão 2.10 modela a energia de ângulo simples para interação entre três átomos ligados $I, J$ e $K$.

$$
E_{\theta}=\frac{1}{2} K_{I J K}\left(\theta_{I J K}-\theta_{0}\right)^{2}
$$

em que $K_{I J K}$ e $\theta_{0}$ representam a constante de força e o ângulo de equilíbrio respectivamente, e $\theta_{I J K}$ está relacionado às orientações de $I J$ e $J K$.

A energia de torsão para interação entre quatro átomos $I, J, K$ e $L$, com ligações $I J, J K, K L$, está associada ao ângulo $\varphi_{I J K L}$ entre os planos formados pelos átomos $I J K$ e $J K L$. Duas diferentes formas para $E_{\varphi}$ são dadas pelas equações 2.11 e 2.12 ,

$$
E_{\varphi}=\frac{V_{I J K L}}{2}\left[1-b \cos n \varphi_{I J K L}\right]
$$

e

$$
E_{\varphi}=\frac{V_{I J K L}}{2}\left[1+\cos \left(n \varphi_{I J K L}+\varphi_{0}\right)\right]
$$

com os parâmetros $V_{I J K}$, representando a amplitude da barreira de energia, $n$ a periodicidade da função, $\varphi_{0}$ o deslocamento angular e $b= \pm 1$.

O termo para energia de inversão, $E_{\omega}$, representa a interação fora do plano entre quatro átomos $I, J, K$ e $L$, com $\omega_{I J K L}$ associado ao ângulo entre a ligação $I L$ e o 
plano $I J K$. De acordo com o ângulo de equilíbrio $\omega_{0}$, temos duas expressões para $E_{\omega}$, sendo $K_{I J K L}$ a constante de força:

$$
E_{\omega}=\frac{K_{I J K L}}{2 \sin ^{2} \omega_{0}}\left(\cos \omega_{I J K L}-\cos \omega_{0}\right)^{2}, \quad \text { para } \omega_{0} \neq 0
$$

$\mathrm{e}$

$$
E_{\omega}=K_{I J K L}\left(1-\cos \omega_{I J K L}\right), \quad \text { para } \omega_{0}=0 .
$$

Para as interações não ligadas temos o termo de Coulomb e o termo de dispersão de Lennard-Jones. O termo de Lennard-Jones, $E_{L J}$, é descrito pela equação 2.15, com $D_{I J}$ representando a profundidade do poço e $r_{0}$ a distância de equilíbrio:

$$
E_{L J}=D_{I J}\left[-2\left(\frac{r_{I J}}{r_{0}}\right)^{6}+\left(\frac{r_{I J}}{r_{0}}\right)^{12}\right] .
$$

Esta forma para o potencial pode ser também escrita como:

$$
E_{L J}=\frac{-C_{6}}{r_{0}^{6}}+\frac{C_{12}}{r_{0}^{12}}
$$

onde

$$
C_{6} \equiv 2 D_{I J}\left(r_{I J}\right)^{6} \quad \text { e } \quad C_{12} \equiv D_{I J}\left(r_{I J}\right)^{12}
$$

Já a energia eletrostática é calculada pela equação 2.18, onde $Q_{I}$ e $Q_{J}$ são cargas efetivas atribuídas aos átomos $I$ e $J, r_{I J}$ a distância, e C uma constante dimensional.

$$
E_{e l}=\frac{C Q_{I} Q_{J}}{r_{I J}}
$$

No uso do UFF dentro do pacote Cerius $^{2}$, a inclusão de interação eletrostática fica a critério do usuário. As cargas podem ser nulas, fixadas em algum valor escolhido ou determinadas pelo método de equilíbrio de cargas [27] (charge equilibration, Qeq), também presente no Cerius ${ }^{2}$. Na nossa reparametrização, que será descrita adiante, optamos por fixar as cargas atômicas em valores obtidos por modelamento baseado em cálculos quânticos [28] (seção 2.2.4). Ao usarmos o UFF, utilizamos ou cargas nulas ou o Qeq para comparação. 


\subsubsection{Módulo de Compressibilidade (Bulk Modulus - B)}

Como já mencionamos neste trabalho procedemos à reparametrização do UFF; além de propriedades estáticas, como por exemplo a constante de rede do Si, para análise do comportamento em temperatura, são muito importantes as propriedades elásticas.

Utilizamos o módulo de propriedades mecânicas do Cerius $^{2}$ [24] para obtenção do coeficiente de compressibilidade térmica e do módulo de compressibilidade. Os cálculos podem ser feitos através de três métodos: segunda derivada, minimização das constantes de stress e minimização das constantes de strain. Em nossos cálculos, utilizamos o método de segunda derivada para obtenção das segundas derivadas da energia na rede, com respeito ao parâmetro de rede e coordenadas atômicas. A expressão utilizada para energia é dada por:

$$
U=U_{0}+\sum_{i} \frac{\partial U}{\partial \varepsilon} \varepsilon_{i}+\frac{1}{2} \sum_{i j} \frac{\partial^{2} U}{\partial \varepsilon_{i} \partial \varepsilon_{j}} \varepsilon_{i} \varepsilon_{j},
$$

em que $U_{0}$ é a energia de equlíbrio e $\varepsilon$ o strain. Quando a estrutura está em um mínimo de energia (derivadas de primeira ordem da energia da malha nulas) os termos de derivada segunda são usados para calcular as componentes, $C_{i j}$ de uma matriz que chamaremos de matriz stiffness (C), definida em termos destas componentes

$$
C_{i j}=\frac{\partial^{2} U}{\partial \varepsilon_{i} \partial \varepsilon_{j}} .
$$

A matriz stiffness obtida por este método é simétrica, ou seja, $C_{i j}=C_{j i}$. Definindose a matriz compliance, $\mathbf{S}$, como o inverso de $\mathbf{C}$,

$$
\mathbf{S}=\mathbf{C}^{-1}
$$

os coeficientes da matriz, $S_{i j}$, são utilizados para obter quaisquer das propriedades mecânicas do sistema investigado. Em nossos cálculos, estamos interessados no módulo de compressibilidade ou bulk modulus, B, definido como:

$$
B \equiv-V\left(\frac{\partial P}{\partial V}\right)_{T}
$$


em que $T, V$ e $P$, denotam a temperatura, volume e pressão respectivamente. Fisicamente, $B$ é uma função da temperatura e da pressão, sendo por definição sempre positivo, podendo também ser obtido como o inverso do coeficiente de compressibilidade térmica, $k_{T}$

$$
B=\frac{1}{k_{T}}
$$

O coeficiente de compressibilidade térmica é obtido através da soma das componentes de $\mathbf{S}$ como segue:

$$
k_{T}=\sum_{i, j=1}^{3} S_{i j}
$$

e o bulk modulus é portanto calculado através da equação 2.23 .

\subsection{Metodologia Quântica}

A informação física de um sistema poliatômico no limite não relativístico pode ser escrita na forma da função de onda total $\Psi(\vec{R}, \vec{r})$, onde $\vec{R}$ e $\vec{r}$ denotam o conjunto das coordenadas dos núcleos e dos elétrons, respectivamente. Utilizando a aproximação de Born-Oppenheimer [29], podemos separar da função de onda total a parte nuclear, $\phi(\vec{R})$, da parte eletrônica, $\psi(\vec{r} ; \vec{R})$, de forma que $\Psi(\vec{R}, \vec{r})=\phi(\vec{R}) \psi(\vec{r} ; \vec{R})$. A função de onda eletrônica $\psi(\vec{r} ; \vec{R})$ depende explicitamente das coordenadas eletrônicas $\vec{r}$ e parametricamente das nucleares $\vec{R}$. Nestas condições, a equação de Schrödinger para um sistema de muitos elétrons é dada por:

$$
\left[\sum_{i}^{N}\left(-\frac{\hbar^{2} \nabla_{i}^{2}}{2 m}+v\left(\overrightarrow{r_{i}}\right)\right)+\sum_{i<j} U\left(\overrightarrow{r_{i}}, \overrightarrow{r_{j}}\right)\right] \psi\left(\overrightarrow{r_{1}}, \ldots, \overrightarrow{r_{N}}\right)=E \psi\left(\overrightarrow{r_{1}}, \ldots, \overrightarrow{r_{N}}\right)
$$

em que N é o número de elétrons e $U\left(\overrightarrow{r_{i}}, \overrightarrow{r_{j}}\right)$ é a energia de interação elétron-elétron, que pode ser escrita como:

$$
\widehat{U}=\sum_{i<j} U\left(\overrightarrow{r_{i}}, \overrightarrow{r_{j}}\right)=\sum_{i<j} \frac{q^{2}}{\left|\overrightarrow{r_{i}}-\overrightarrow{r_{j}}\right|}
$$


sendo $q$ a carga eletrônica. Da equação 2.25, podemos definir um operador energia cinética como:

$$
\widehat{T}=-\frac{\hbar^{2}}{2 m} \sum_{i} \nabla_{i}^{2},
$$

e um potencial de interação devido às interações elétron-núcleo como:

$$
\widehat{V}=\sum_{i} v\left(\overrightarrow{r_{i}}\right)=\sum_{i k} \frac{Q_{k} q}{\left|\overrightarrow{r_{i}}-\overrightarrow{R_{k}}\right|}
$$

onde a soma em k se estende por todos os núcleos do sistema, cada qual com carga $Q_{k}=Z_{k} q$, e posicionado em $R_{k}$ [30].

Para um sistema de $\mathrm{N}$ elétrons, estaremos interessados em resolver a equação 2.25. Um dos métodos bastante conhecidos para torná-la tratável é o de HartreeFock, sendo a função de onda total o objeto fundamental neste tratamento. Uma outra maneira de tratar este problema, em que o objeto fundamental é a densidade eletrônica $\rho(\vec{r})$, foi apresentado por Hohenberg e Kohn [31] e constitui a base da teoria conhecida como Teoria do Funcional da Densidade. Neste tratamento, como veremos adiante, o problema de $\mathrm{N}$ elétrons, com função de onda de $3 \mathrm{~N}$ variáveis, se reduz a um problema de 3 variáveis.

\subsubsection{Teoria do Funcional da Densidade - DFT}

A Teoria do Funcional da Densidade está fundamentada em dois teoremas propostos por Hohenber e Kohn (HK) [31].

- Teorema 1: O potencial externo $v(\vec{r})$ sentido pelos elétrons é um funcional único da densidade eletrônica $\rho(\vec{r})$.

- Teorema 2: A energia do estado fundamental $E_{0}(\rho)$ é mínima para a densidade extata $\rho(\vec{r})$

$$
E[\rho]=\langle\psi|\widehat{T}+\widehat{U}+\widehat{V}| \psi\rangle
$$

A equação 2.29 pode ser reescrita como segue:

$$
E[\rho]=\langle\psi|\widehat{T}+\widehat{U}| \psi\rangle+\langle\psi|\widehat{V}| \psi\rangle
$$


$\mathrm{Ou}$

$$
E[\rho]=F[\rho]+\langle\psi|\widehat{V}| \psi\rangle
$$

onde $F[\rho]$ é um funcional universal, válido para qualquer sistema coulombiano e, o termo $\langle\psi|\widehat{V}| \psi\rangle$ depende do sistema em questão [32]. Da equação 2.31, podemos escrever

$$
E\left[\rho_{0}\right]=F\left[\rho_{0}\right]+\left\langle\psi_{0}|\widehat{V}| \psi_{0}\right\rangle
$$

em que $\psi_{0}$ é a função de onda do estado fundamental. Notemos que os resultados desta seção são extremamente gerais e os teoremas de HK asseguram que conhecendo $\rho_{0}$, podemos obter todas as propriedades do estado fundamental do sistema.

É conveniente separar do funcional $F(\rho)$ a parte coulombiana clássica (potencial de Hartree),

$$
F[\rho]=\underbrace{\frac{1}{2} \iint \frac{\rho(\vec{r}) \rho\left(\overrightarrow{r^{\prime}}\right)}{\left|\vec{r}-\overrightarrow{r^{\prime}}\right|} d^{3} r d^{3} r^{\prime}}_{U_{H}}+G[\rho]
$$

em que

$$
G[\rho]=U[\rho]-U_{H}+T[\rho] .
$$

A equação 2.31 é escrita como:

$$
E[\rho]=\int v(\vec{r}) \rho(\vec{r}) d^{3} r+\frac{1}{2} \iint \frac{\rho(\vec{r}) \rho\left(\overrightarrow{r^{\prime}}\right)}{\left|\vec{r}-\overrightarrow{r^{\prime}}\right|} d^{3} r d^{3} r^{\prime}+G[\rho] .
$$

\subsubsection{Equações de Kohn-Sham}

Kohn e Sham (KS) [33] foram os primeiros a apresentar uma estratégia para o cálculo da estrutura eletrônica de um sistema de muitas partículas com o uso de $E[\rho]$, equação 2.35. A sugestão de KS foi escrever o funcional energia cinética como segue; em termos de orbitais $\psi_{i}$ de um elétron:

$$
T_{0}[\rho]=-\frac{1}{2} \sum_{i} \int \psi_{i}^{*} \nabla^{2} \psi_{i} d^{3} r
$$

com a densidade de carga

$$
\rho(\vec{r})=\sum_{i=1}^{N}\left|\psi_{i}(\vec{r})\right|^{2}
$$


Os orbitais de um eletron, $\psi_{i}$, podem ser obtidos resolvendo a equação de Schrödinger de uma partícula, na aproximação de determinante de Slater (combinação antissimétrica de funções de um elétron) para a função de onda total

$$
\left(-\frac{1}{2} \nabla^{2}+v^{K S}[\rho]\right) \psi_{i}(\vec{r})=\epsilon_{i} \psi_{i}(\vec{r})
$$

onde $v^{K S}[\rho]$ é o potencial efetivo de KS dado por

$$
v^{K S}=v(\vec{r})+\int \frac{\rho\left(\overrightarrow{r^{\prime}}\right)}{\left|\vec{r}-\overrightarrow{r^{\prime}}\right|} d^{3} r^{\prime}+v_{x c}(\rho)
$$

sendo $v_{x c}(\rho)$ o responsável por introduzir os efeitos de troca e correlação. Na aproximação de $\mathrm{KS}$, podemos reescrever o funcional $G[\rho]$ (equação 2.34) como:

$$
G[\rho]=T_{0}[\rho]-U_{H}+E_{x c}[\rho]
$$

onde $T_{0}[\rho]$ é a parte da energia cinética de um sitema de elétrons não interagentes com densidade $\rho(\vec{r})$, e $E_{x c}[\rho]$ contém a energia de troca e correlação devido à interação de muitos corpos. Assim, o funcional da energia, equação 2.35, pode ser reescrito como:

$$
E[\rho]=\int v(\vec{r}) \rho(\vec{r}) d^{3} r+\frac{1}{2} \iint \frac{\rho(\vec{r}) \rho\left(\overrightarrow{r^{\prime}}\right)}{\left|\vec{r}-\overrightarrow{r^{\prime}}\right|} d^{3} r d^{3} r^{\prime}+T_{0}[\rho]+\int \rho(\vec{r}) E_{x c}(\rho(\vec{r})) d^{3} r
$$

Para resolver a equação 2.41, precisamos ainda de uma aproximação para o termo de troca e correlação.

\subsubsection{Aproximações para Troca e Correlação}

Na aproximação LDA (Local Density Approximation) supõe-se que $\rho(\vec{r})$ varia suavemente nas proximidades do ponto $\vec{r}$, assim escreve-se

$$
E_{x c}[\rho]=\int \rho(\vec{r}) \epsilon_{x c}^{h}(\rho(\vec{r})) d^{3} r
$$

onde $\epsilon_{x c}^{h}(\rho)$ é a energia de troca e correlação por elétron de um gás de elétrons homogêneo de densidade $\rho=\rho(\vec{r})$. Existem várias propostas para o termo $E_{x c}$, mas 
independentemente da parametrização, na aproximação LDA o termo $E_{x c}[\rho]$ é dado por:

$$
E_{x c}[\rho] \cong E_{x c}^{L D A}[\rho]=\int d^{3} r \rho(\vec{r})\left[\epsilon_{x}(\rho(\vec{r}))+\epsilon_{c}(\rho(\vec{r}))\right],
$$

onde se separa o termo de troca, $\epsilon_{x}$, que para um gás homogêneo é obtido facilmente e exatamente, e o termo de correlação, $\epsilon_{c}$, que não é obtido exatamente [32]. O termo $\epsilon_{c}$, foi obtido por Cerpeley e Alder [34] utilizando o método de Monte Carlo, e utilizado por Perdew e Zunger [35] para parametrização de $E_{x c}$.

Um refinamento do método LDA é expressar o funcional de troca e correlação em termos também do gradiente da densidade de carga, ficando o funcional $E_{x c}$ escrito como [32]:

$$
E_{x c}^{G G A}[\rho]=\int d^{3} r f(\rho(\vec{r}), \nabla \rho(\vec{r})) .
$$

Essa aproximação, conhecida como expansão generalizada em termos de gradientes (GGA), é adotada na tentativa de corrigir efeitos de não homogeneidade na densidade. Existem várias propostas para $E_{x c}^{G G A}$, atualmente as mais utilizadas são baseadas nos trabalhos de Perdew-Burke-Erzenhof [36] e de Perdew-Wang [37].

\subsubsection{Cargas de Hirshfeld}

Uma vez obtida a densidade eletrônica $\rho(\vec{r})$ no espaço, o valor da carga de um "átomo na molécula" pode ser calculado por diferentes metodologias. O método de Hirshfeld [28] é uma das propostas para tal, e parte da idéia de uma "proto-molécula", ou seja, uma distribuição eletrônica que seja simplismente a soma de densidades de átomos "livres" mas na geometria da molécula real: a densidade eletrônica $\rho_{p}(\vec{r})$ da proto-molécula é assim definida como $\sum_{A^{\prime}} \rho_{A^{\prime}}(\vec{r})$, onde $\rho_{A}(\vec{r})$ é a densidade do átomo A livre. Dessa forma, a fração da densidade eletrônica correspondente ao átomo A, $\omega_{A}(\vec{r})$, em um ponto do espaço na proto-molécula será definida pela equação 2.45 :

$$
\omega_{A}(r)=\frac{\rho_{A}(\vec{r})}{\sum_{A^{\prime}} \rho_{A^{\prime}}(\vec{r})} .
$$


Segundo o método de Hirshfeld, a densidade eletrônica correspondente ao átomo A na molécula real $\left(\rho_{A}^{\text {lig }}(\vec{r})\right)$ será dada por:

$$
\rho_{A}^{l i g}(\vec{r})=\omega_{A}(\vec{r}) \rho^{m o l}(\vec{r}),
$$

sendo $\rho^{m o l}(\vec{r})$ a densidade eletrônica da molécula real. Assim, a carga de Hirshfeld $\left(Q_{A}\right)$ efetiva para o átomo A é dada por:

$$
Q_{A}=Z_{A}-\int d^{3} r \rho_{A}^{l i g}(\vec{r})
$$

onde $Z_{A}$ é o número atômico do átomo em questão. Este método é assim pefeitamente consistente com a DFT e foi utilizado, como descreveremos a seguir, para inclusão da energia de dispersão por Tkatchenko e Scheffler [38].

\subsubsection{Interação de van der Waals}

Tanto os funcionais LDA quanto GGA apresentam problemas na obtenção de parâmetros como constantes de rede, bulk modulus e principalmente conformações quando o sistema é não ligado. Nesse caso, a inclusão na DFT das interações de van der Waals torna-se fundamental. Optamos por utilizar a inclusão das interações conforme proposta de Tkatchenko-Scheffler (TS) [38], implementada no programa FHI-AIMS (The Ab initio Molecular Simulations Package) [39], desenvolvido recentemente no FHI - Fritz Haber Institute de Berlim. O código computacional é baseado em DFT e utiliza um conjunto de base localizado all-electron para descrição da estrutura eletrônica de sistemas isolados ou sistemas periódicos conforme veremos na seção 2.3.3.

De acordo com a proposta de TS [38], para definirmos o coeficiente $\mathrm{C}_{6}$ para um átomo numa molécula ou sólido (equações 2.16, 2.17 e 2.49), podemos utilizar a razão entre o volume efetivo do átomo na molécula/sólido e o volume ocupado pelo átomo livre (no vácuo). Consideram uma relação direta entre polarizabilidade e volume, e empregam o método da partição de Hirshfeld para determinar esse volume efetivo. 
A relação entre a polarizabilidade e volume é dada por

$$
\frac{\kappa_{A}^{e f f}}{\kappa_{A}^{\text {free }}} \frac{\alpha_{A}^{\text {eff }}}{\alpha_{A}^{f r e e}}=\frac{V_{A}^{e f f}}{V_{A}^{\text {free }}},
$$

e o coeficiente efetivo $C_{6 A A}^{e f f}$ para um átomo na molécula é determinado pela equação:

$$
C_{6 A A}^{\text {eff }}=\frac{\eta_{A}^{\text {eff }}}{\eta_{A}^{\text {free }}}\left(\frac{\kappa_{A}^{\text {free }}}{\kappa_{A}^{\text {eff }}}\right)^{2}\left(\frac{V_{A}^{\text {eff }}}{V_{A}^{\text {free }}}\right)^{2} C_{6 A A}^{\text {free }},
$$

em que $\eta_{A}^{f r e e}$ e $\eta_{A}^{e f f}$ são a frequência característica do átomo A, livre e na molécula respectivamente. Na equação 2.49 é feita a seguinte aproximação

$$
\frac{\eta_{A}^{\text {eff }}}{\eta_{A}^{\text {free }}}\left(\frac{\kappa_{A}^{\text {free }}}{\kappa_{A}^{\text {eff }}}\right)^{2} \rightarrow 1
$$

considerada boa para uma grande variedade de moléculas [38]. O raio de van der Waals (raio de vdw) para um átomo numa molécula é dado por:

$$
R_{e f f}^{0}=\left(\frac{V_{A}^{e f f}}{V_{A}^{f r e e}}\right)^{1 / 3} R_{\text {free }}^{0} .
$$

O raio de vdW corresponde à metade da distância entre dois átomos, quando a repulsão de Pauli equilibra a atração de dispersão de London [38]. Segundo a definição, o raio de vdW de átomos livres, $R_{\text {free }}^{0}$, para átomos em gases raros corresponde à distância de equilíbrio dos dímeros. Para outros elementos não podemos utilizar o mesmo raciocínio para obter o raio de vdW, uma vez que correspondem a átomos em moléculas. Neste caso, o procedimento sugerido por TS é que se utilize o resultado para átomos de gases raros para definir $R_{\text {free }}^{0}$ para elementos na mesma linha da tabela periódica.

Utilizando as equações 2.49 e 2.51, podemos reescrever 2.17 para obtermos os pares $\mathrm{r}_{I J}$ e $\mathrm{D}_{I J}$ que serão diretamente utilizados na parametrização do UFF. Um ponto importante é que, devido à aproximação dada pela equação 2.50, os valores de $\mathrm{D}_{I J}$ só dependem dos valores de $\mathrm{C}_{6}$ e $\mathrm{r}_{I J}$ de átomos livres. Portanto, para um dado tipo atômico, o valor de $\mathrm{D}_{I J}$ é constante e independente do sistema estudado. Detalhes da reparametrização serão descritos na seção 3.3. 


\subsection{Métodos DFT}

Empregamos para resolver as equações de KS os códigos computacionais ESPRESSO [40] e FHI-AIMS [39], que permitem o cálculo de forças sobre os núcleos, e "otimizações de geometria".

\subsubsection{Código ESPRESSO e Base de Ondas Planas}

Em sistemas periódicos, o uso de funções de base tipo ondas planas (plane waves PW) torna mais simples a representação dos orbitais de KS. A expansão dos orbitais de KS em termos dos vetores da rede recíproca $\vec{G}$ e vetores de onda da primeira zona de Brillouin (ZB) $\vec{k}$ é dada por

$$
\psi_{i}(\vec{r})=\frac{e^{i \vec{k} \cdot \vec{r}}}{\sqrt{\Omega}} \sum_{\vec{G}=0}^{\infty} C_{i \vec{k}}(\vec{G}) e^{i \vec{G} \cdot \vec{r}}=\sum_{\vec{G}=0}^{\infty} C_{i \vec{k}}(\vec{G}) \frac{1}{\sqrt{\Omega}} e^{i(\vec{k}+\vec{G}) \cdot \vec{r}}=\sum_{\vec{G}=0}^{\infty} C_{i \vec{k}}(\vec{G}) \phi_{\vec{G}}^{\vec{k}}(\vec{r}),
$$

em que $\Omega$ é o volume do cristal e a energia cinética máxima das PWs pode ser escrita como:

$$
\frac{\hbar^{2}}{2 m}|\vec{k}+\vec{G}|^{2} \leq E_{\text {cut }} .
$$

O termo $\mathrm{E}_{\text {cut }}$ na equação 2.53 é o valor de energia para o qual encerramos a expansão 2.52. Os coeficientes de Fourier $\mathrm{C}_{\vec{k}}(\vec{G})$ decrescem rapidamente com o aumento da energia de corte das ondas PW, portanto a verificação da convergência das propriedades físicas em função do tamanho da função de base é razoavelmente simples. A densidade eletrônica é dada por

$$
\rho(\vec{r})=\frac{2}{\Omega N_{k p t}} \sum_{\vec{k}} f_{\vec{k} i} \sum_{\vec{G}, \vec{G}^{\prime}} C_{i \vec{k}}^{*}\left(\vec{G}^{\prime}\right) C_{i \vec{k}}(\vec{G}) e^{-i\left(\vec{k}+\vec{G}^{\prime}\right) \cdot \vec{r}} e^{i(\vec{k}+\vec{G}) \cdot \vec{r}}
$$

onde a ocupação do orbital é dada por $\mathrm{f}_{\vec{k} i}$, e $\mathrm{N}_{k p t}$ define o número de pontos $\vec{k}$ da grade numérica do espaço recíproco.

Cálculos computacionais usando funções do tipo PW tornam-se inviáveis para descrever regiões próximas ao núcleo atômico, caso em que as funções de onda apresentam muitas oscilações. Uma maneira de contornar este problema é aproximação do pseudopotencial. 


\subsubsection{Código ESPRESSO e Pseudopotenciais}

Na descrição das ligações químicas e propriedades de sólidos, os elétrons mais externos ou de valência contribuem mais significativamente que os elétrons mais internos ou de caroço. Não deixaremos de descrever as propriedades relevantes do sistema em questão se substituirmos a função de onda, na região de caroço, por uma pseudofunção de onda sem nós (que não é solução do problema atômico original) enquanto nas regiões mais externas se aproxima rapidamente da solução exata. Uma vantagem do uso de pseudopotencias é que o número de orbitais de KS a serem avaliados é reduzido e o uso de PW torna-se viável.

\section{Pseudopotenciais de Norma Conservada}

Um pseudopotencial é construído a partir da resolução numérica da equação de Schrödinger. Para isso, substituímos o potencial de KS dentro de uma esfera de raio $R_{\text {cut }}$ por um pseudopotencial suave. Os pseudopotenciais devem ser capazes de descrever o átomo em ambientes químicos diferentes. Uma propriedade importante é que a integral da densidade de carga no interior de uma esfera de raio $\mathrm{R}_{c u t}$ seja idêntica àquela obtida para a função de onda original. Os pseudopotenciais que respeitam esta condição são denominados de pseudopotenciais de norma conservada, o que garante boa transferibilidade dos mesmos. Alguns dos potencias bem sucedidos são aqueles desenvolvidos por Troullier-Martins (TM) [41] e a proposta alternativa de Rappé e colaboradores (RRKJ) [42].

\section{Pseudopotenciais "Ultrasuaves"}

Na aproximação de pseudopotencial pretende-se criar pseudofunções de onda suave com a maior precisão possível. A conservação da norma garante a precisão, no entanto, é o principal motivo na diminuição da suavidade de pseudopotenciais. O problema pode ser contornado utilizando pseudopotenciais denominados "ultrasuaves", construídos segundo a proposta de Vanderbilt [43]. Neste caso, a conservação da 
norma não é satisfeita por construção, permitindo o aumento de $R_{c u t}$. Os pseudopotenciais "ultrasuaves" vem sendo bastante utilizados, principalmente quando os orbitais de KS são expandidos em PWs [21], caso em que o custo computacional para avaliar a correção da densidade é relativamente baixo.

\subsubsection{Código FHI-AIMS e Bases Locais}

O código computacional FHI-AIMS [39] é também baseado na DFT, mas não emprega pseudopotenciais. Utiliza um conjunto de base localizado all-electron para cálculos tanto de moléculas isoladas, como para sistemas periódicos

Um importante diferencial do AIMS em relação aos demais códigos computacionais que utilizam base local é a possibilidade de escolha das funções de base de orbitais atômicos numéricos (OANs). O uso de OANs é fundamental na precisão e eficiência de cálculos de estrutura eletrônica realizados com este código. Segundo a idéia originalmente proposta [39,44], a função de onda dos orbitais de uma partícula, $\psi_{l}(r)$, utilizada na solução das equações de KS, é expandida em termos de funções de base $\varphi_{i}(r)$, que são escritas como um produto de um termo radial, $u(r)$, e harmônicos esféricos, $Y_{l m}(\Omega)$, (Equação 2.55).

$$
\psi_{l}(r)=\sum_{i=1}^{N_{b}} c_{i l} \varphi_{i}(r), \text { onde } \varphi_{i}(r)=\frac{u_{i}(r)}{r} Y_{l m}(\Omega)
$$

A forma radial das funções $\varphi_{i}(r)$ é tabelada numericamente, o que nos permite a determinação de um conjunto de bases otimizadas para cada elemento da tabela periódica, incluindo correções relativísticas para elementos mais pesados, com um nível de precisão da ordem de meV para convergência na energia total. Uma descrição mais detalhada deste método pode ser encontrada nas referências [39] e [44].

A literatura mostra um boa transferabilidade das bases OANs do FHI-AIMS para uma ampla variedade de sistemas moleculares e periódicos $[45,46]$.

A principal justificativa para utilização do FHI-AIMS no nosso trabalho vem da possibilidade de calcularmos, de forma consistente, as cargas a serem atribuídas aos 
átomos na molécula através do procedimento de Hirshfeld, e os dos coeficientes de dispersão TS conforme descrito na seção 2.2.5, utilizando uma metodologia totalmente $a b$ initio. Neste caso, é possível incluir estas interações nos funcionais padrão da DFT [39], que são extremamante importantes para os sistemas investigados neste trabalho. 


\section{Capítulo 3}

\section{Reparametrização do UFF}

Neste capítulo o objetivo é apresentar a metodologia utilizada na reparametrização das interações ligadas e de longo alcance do campo de força UFF. Para tal, discutimos os resultados de cálculos ab initio para o Si, tanto cristalino, quanto para superfícies hidrogenadas: $\operatorname{Si}(100)(2 x 1): H, \operatorname{Si}(100)(1 x 1): 2 H, S i(100)(3 x 1): H, S i(111)(1 x 1): H$. Além do Si, discutimos também resultados para a molécula de estireno. Essas discussões são acompanhadas pelos resultados de cálculos com os campos de força padrão. Descrevemos quais dados dos cálculos de primeiros princípios foram utilizados no processo de reparametrização e sempre que possível, estudamos a estrutura eletrônica dos sistemas investigados neste trabalho através da geometria obtida com nosso campo de força. Sendo a reparametrização apenas em alguns termos do UFF o novo campo é batizado de UFFN. Optamos por dispor todas as tabelas deste capítulo no final da seção 3.3.2 para uma maior facilidade de leitura do texto.

\subsection{Cálculos de Primeiros Princípios}

Para o Si bulk realizamos um cálculo DFT/GGA/PBE (tabela 3.1), relaxando a célula unitária primitiva e as posições atômicas dos dois átomos na célula. Neste caso empregamos pseudopotencial utrasoft e utilizamos o código computacional ESPRESSO [40]. Os resultados foram calculados com energia de corte de ondas 
planas de 30 Ry e corte da densidade de carga de 300 Ry. Utilizamos 60 pontos k especiais, gerados através do esquema de Monkhorst-Pack [47], para a integração das equações de Kohn-Sham. Na tabela 3.1 incluímos dados experimentais [1,48] e teóricos $\mathrm{DFT} / \mathrm{LDA} / \mathrm{PZ}$ [6] da literatura para comparação. Os parâmetros estruturais obtidos com os campos de força clássicos (com carga atômica nula) também dispostos na mesma tabela serão analisados na seção 3.2.

Calculamos as cargas da molécula de estireno isolada, da superfície de Si hidrogenada, e também do sistema híbrido. A tabela 3.2 mostra as cargas atômicas obtidas por diferentes métodos para a molécula de estireno, ilustrada na Figura 3.1. Para simularmos a molécula isolada utilizamos os códigos ESPRESSO [40] e FHI-

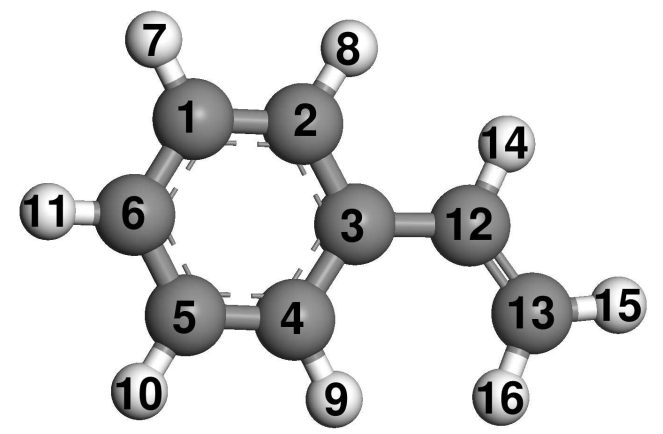

Figura 3.1: Molécula isolada de estireno. Os números se referem à etiqueta que adotaremos para designar os átomos. Os átomos em cinza mais escuro são de carbonos e os demais de hidrogênio.

AIMS [39]. No ESPRESSO a geometria otimizada foi obtida utilizando uma caixa ortorrômbica com os seguintes parâmetros: $a=22,00 \AA, b=18,00 \AA, c=15,00 \AA$ (menor distância entre a molécula e sua imagem periódica de 15,00A). Os valores da energia de corte das ondas planas e da densidade eletrônica foram os mesmos utilizados para o Si bulk.

No FHI-AIMS realizamos um cálculo de energia total para a molécula isolada utilizando as coordenadas otimizadas no ESPRESSO. Ambos os cálculos foram realizados com funcional GGA/PBE.

Um ponto interessante é a carga obtida para o átomo de carbono 3 (Figura 3.1), 
ligado a outros 3 átomos de C, que para o método de Lowdin adquire carga positiva, e significativa. A carga de Hirshfeld para o átomo 3 é muito próxima de zero e negativa. Este tem sido um resultado comum a outros sistemas orgânicos com átomos de C nessa coordenação, obtido por outros componentes do grupo Nanomol. Temos na mesma tabela também cargas obtidas através do método Qeq que discutiremos mais adiante.
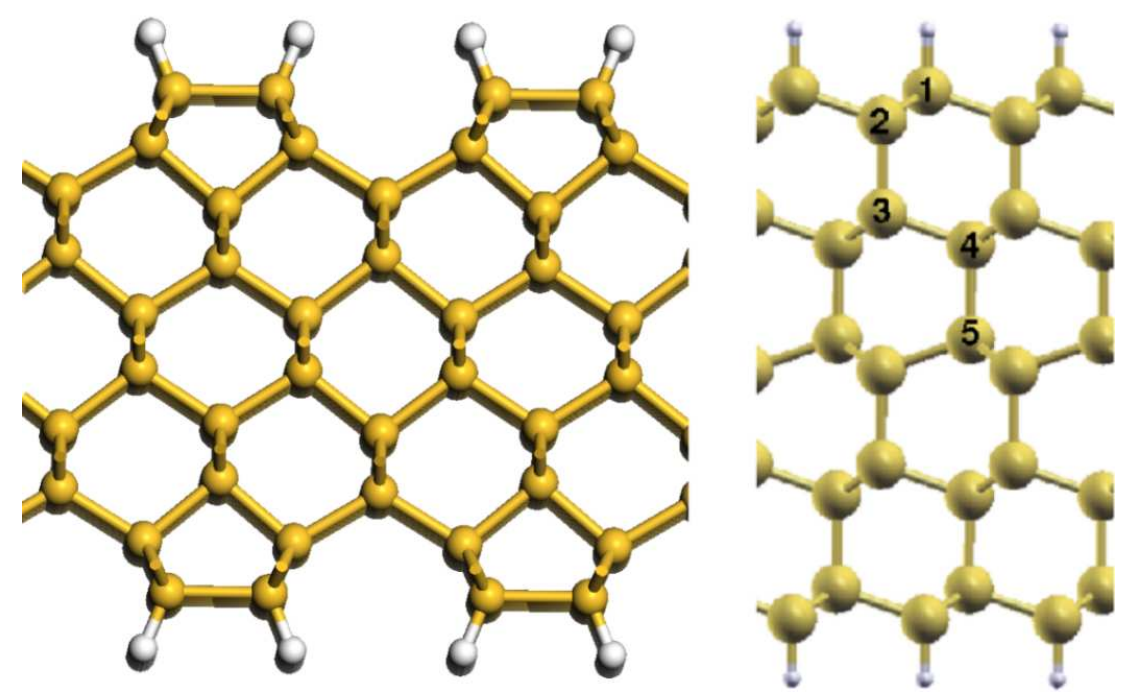

Figura 3.2: Modelos para as superfícies $\operatorname{Si}(100)(2 \mathrm{x} 1): \mathrm{H}$ e $\mathrm{Si}(111)(1 \times 1): \mathrm{H}$ com 10 camadas.

Para simularmos a superfície de $\operatorname{Si}(100)(2 \times 1)$ :H utilizamos uma fatia (reconstruída de ambos os lados) 2x1 de 10 camadas. Para esta superfície, teremos, nas direções cartesianas $\mathbf{x}$ e $\mathbf{y}$, parâmetros de rede da fatia dados por $\sqrt{2} a \times \frac{\sqrt{2}}{2} a$, onde $a$ é o parâmetro de rede do Si em sua forma bulk (tabela 3.1). Na direção perpendicular à fileira de dímeros, temos imagens da superfície separadas por uma região de "vácuo" de 20 Å. Otimizamos as posições atômicas com energia de corte de ondas planas de 25 Ry, corte da densidade de carga de 250 Ry e utilizando 18 pontos k especiais. A geometria otimizada foi então empregada para um cálculo no FHI-AIMS. Os resultados para as cargas atômicas da Si(100)(2x1):H estão dispostos na tabela 3.3, e as etiquetas definidas na Figura 3.3 (a). Um ponto interessante é a 

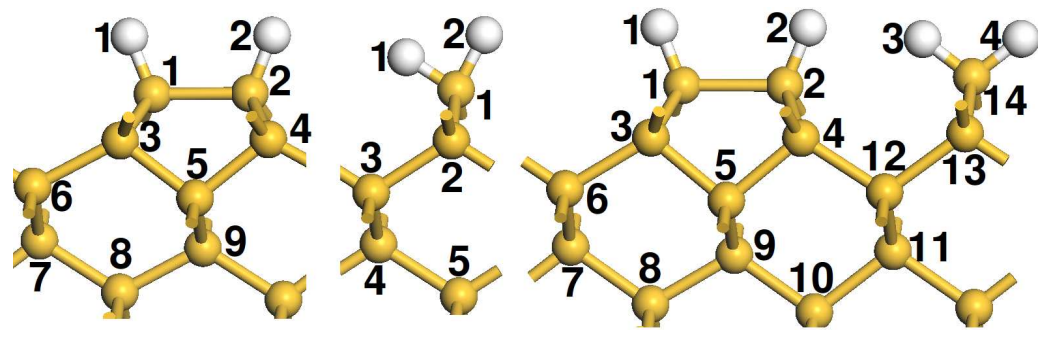

Figura 3.3: Vista lateral das superfícies (a) $\operatorname{Si}(100)(2 \mathrm{x} 1): H,(b) \operatorname{Si}(100)(1 \mathrm{x} 1): 2 \mathrm{H}$ e (c) $\mathrm{Si}(100)(3 \mathrm{x} 1): \mathrm{H}$. Os átomos mais escuros denotam os silícios e os brancos os hidrogênios.

carga negativa dos átomos de $\mathrm{H}$ de superfície, característica deste sistema.

Para a superfície $\operatorname{Si}(100)(2 x 1): H$ funcionalizada com uma molécula de estireno quimissorvida sobre o dímero utilizamos uma fatia (reconstruída de ambos os lados) 4x1 (Figura 3.4). Discutiremos as propriedades energéticas no capítulo 4. Para

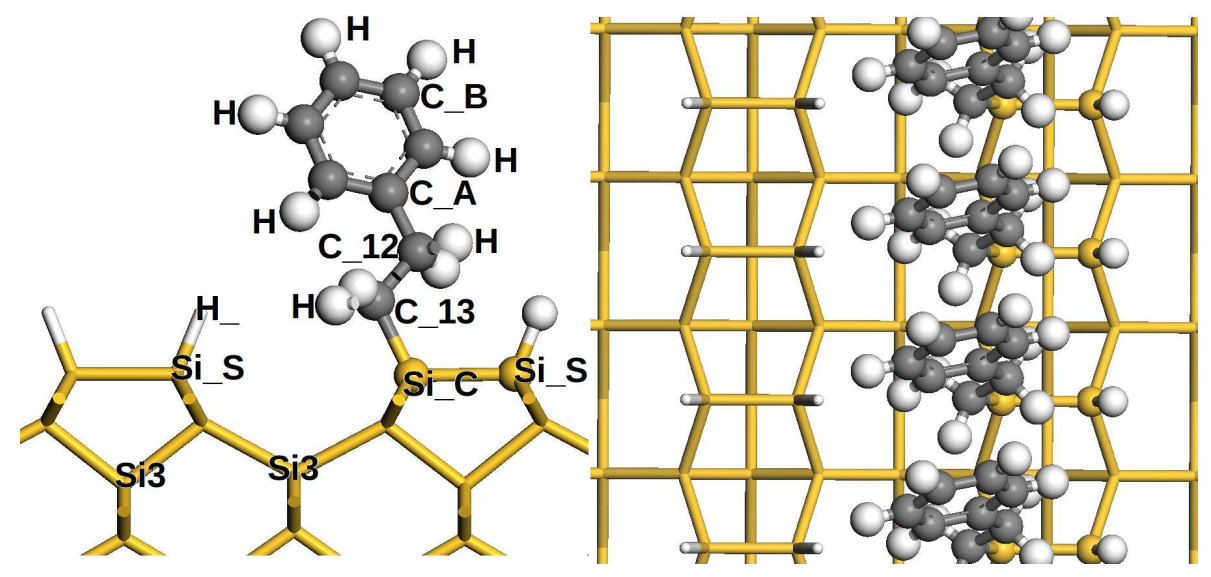

Figura 3.4: Célula unitária $(4 \mathrm{x} 1)$ utilizada no cálculo ab initio das cargas de Hirshfeld para a linha de estireno sobre a $\operatorname{Si}(100)(2 \times 1): H$. Vistas lateral e superior; na vista superior representamos por clareza 4 células unitárias.

esta fatia, teremos, nas direções cartesianas $\mathbf{x}$ e $\mathbf{y}$, parâmetros de rede $2 \sqrt{2} a \times \frac{\sqrt{2}}{2} a$. Excepcionalmente aqui $a$ é o parâmetro de rede do Si em sua forma bulk obtido com o PCFF que difere muito pouco, entretanto, daquela com DFT/PBE. A superfície funcionalizada foi então otimizada utilizando o código FHI-AIMS com funcional 
GGA/PBE , e inclusão das interações de vdW [38]. Neste caso, optamos pelo FHIAIMS devido à interação tipicamente não-ligada entre os átomos da molécula e a superfície

Na tabela 3.4 temos as cargas de Hirshfeld para esse sistema. As etiquetas estão definidas na Figura 3.4. Utilizamos a mesma nomenclatura, Si3, para designar os átomos de Si no volume da fatia da segunda camada atômica em diante, e mostramos na tabela apenas as cargas dos átomos explicitados na figura. Estes átomos exibem valores de cargas muito próximas de zero, e utilizaremos a mesma nomenclatura para os tipos atômicos na construção de UFFN, como veremos na seção 3.3.

Analisando os valores das cargas para os átomos de silício e hidrogênio nos dímeros pristinos da superfície hidrogenada $\mathrm{Si}(100)(2 \mathrm{x} 1): \mathrm{H}$ (tabela 3.3, Figura 3.3 (a)), não notamos diferenças significativas entre valores calculados para estes mesmos átomos na superfície $\mathrm{Si}(100)(2 \mathrm{x} 1)$ :H funcionalizada com a molécula (tabela 3.4, Figura 3.4). Deste modo, as cargas dos silícios e hidrogênios para a linha de estireno são as mesmas utilizadas para a superfície sem a molécula na construção do UFFN, conforme veremos na seção 3.3 .

\subsection{Reparametrização das Interações Ligadas}

Os parâmetros ligados presentes no UFF associados ao H não foram reparametrizados, uma vez que a ligação $\mathrm{Si}-\mathrm{H}$ nas superfícies encontra-se bem descrita, como veremos na seção 3.3. Também não reparametrizamos os parâmetros ligados do C, posto que as ligações C-H e C-C da molécula de estireno encontram-se bem descritas, com diferenças nos comprimentos de ligação não utrapassando $2 \%$ em relação a resultados ab initio (seção 3.3). Assim, reparametrizamos apenas a interação ligada $\mathrm{Si}-\mathrm{Si}$.

A partir da configuração experimental do cristal de silício, relaxamos as posições atômicas do Si bulk com dois campos de força convencionais, presentes no pacote computacional Cerius $^{2}$ [24], a saber: UFF (com carga nula) e PCFF. Os parâmetros 
estruturais obtidos com estes campos estão presentes na tabela 3.1 (seção 3.1).

Nossos resultados mostram que o UFF subestima o parâmetro de rede e as distâncias interatômicas de $\approx 6 \%$ relativamente aos dados experimentais e teóricos (tabela 3.1). Conforme vemos na tabela, o PCFF fornece uma boa descrição do silício cristalino, e desta forma utilizaremos este campo de força em algumas simulações para uma primeira geometria a ser otimizada. Ainda na mesma tabela, temos o módulo de compressibilidade ou bulk modulus (B) do sistema, obtido com os campos de força citados, e também valores experimentais [48] e teóricos [6] de B para comparação . Vemos que em ambos os casos, os resultados clássicos com UFF e PCFF apresentam a mesma ordem de erro ( $\approx 20 \%$ ), não desprezível.

Para uma melhor descrição dos parâmetros estruturais do Si bulk foi necessário, reparametrizarmos apenas o termo $\mathrm{E}_{R}$ que descreve o estiramento da ligação (equação 2.8). A alteração foi aumentar o comprimento de equilíbrio $r_{0}$ na equação 2.8 de 1,12 para $2,37 \AA$, e o valor de $a_{0}$ obtido com o novo campo reparametrizado se aproxima do valor experimental, melhorando significativamente a descrição do cristal.

Mantemos o valor para a constante de força $\left(\mathrm{k}=228,433 \mathrm{kcal} . \mathrm{mol}^{-1}\right)$ utilizada no UFF, que está associada aos modos normais de vibração do sistema, bem como o tipo da aproximação que representa o potencial (harmônica). Denotaremos por $\mathrm{Si} 3$, o tipo atômico caracteristico do átomo de $\mathrm{Si}$ do cristal, com 4 vizinhos de $\mathrm{Si}$ em coordenação tetraédrica. Vemos que o UFFN fornece para o cristal de Si valores dos parâmetros estruturais (distâncias, ângulos, $\mathrm{a}_{0}$ ) e módulo de compressibilidade em excelente concordância com os resultados experimentais e ab initio (tabela 3.1). O erro em $\mathrm{a}_{0}$ diminui de 5,7 para 0,26\%, enquanto o erro no valor de $\mathrm{B}$ diminui de 20,98 para $5,23 \%$. 


\subsection{Reparametrização das Interações de Coulomb e Lennard-Jones}

É usual acoplar o UFF ao método Qeq [27], entretanto já foram identificadas [49] discrepâncias sérias para as cargas atômicas associadas a átomos de enxofre e carbono, calculadas por cálculos ab initio e pelo Qeq. Para solucionar tais problemas, nosso grupo adotou como estratégia nas simulações de DMC empregar cargas obtidas através do método de Hirshfeld/DFT $[28,38]$. Isto implica em obter novos parâmetros de Lennard-Jones (LJ), uma vez que deve haver equilíbrio entre os termos não ligados. Optamos por basear nossa reparametrização em cargas obtidas através do pacote FHI-AIMS [39], mesmo quando as geometrias e demais análises foram obtidas por outro código (seção 3.1), para manter esse equilíbrio pois utilizaremos o modelo de Tkatchenko e colaboradores $[38,50]$ para o termo de van der Waals.

Diferentemente de Rappé e colaboradores, que construíram um campo de força "universal", baseado em regras gerais e para a descrição de todos os elementos da tabela periódica (subseção 2.1.1), aqui desenvolvemos um campo específico para a superfície de $\operatorname{Si}(100)(2 \mathrm{x} 1): H$ funcionalizada com estireno. As cargas atômicas e a vizinhança foram decisivas na escolha dos diferentes tipos atômicos presentes em UFFN e introduzimos 3 tipos atômicos para descrever átomos de Si (Figura 3.4). Os átomos de Si que não pertencem à superfície de Si hidrogenada possuem cargas de Hirshfeld próximas de zero (como o do bulk), enquanto um átomo de superfície mostra carga de 0,0644 (tabela 3.4). Ou seja, a partir da segunda camada da fatia podemos considerar os átomos de Si equivalentes. Por outro lado, os átomos de hidrogênio da superfície de Si (carga negativa) são etiquetados distintamente daqueles da molécula (carga positiva). Listamos abaixo a descrição dos tipos atômicos escolhidos para construção de UFFN e já definidos na Figura 3.4 (seção 3.1):

- $S i$ S denota todos os átomos de Si pertencentes aos dímeros pristinos; Si3 refere-se a todos os átomos de Si da segunda camada da superfície em diante 
e também utilizados para o cristal de $\mathrm{Si}$;

- Si $C$ denota o átomo de Si ligado ao carbono na superfície funcionalizada (Figura 3.4) e que possue carga bem distinta em relação a outros silícios;

- H_ refere-se aos hidrogênios da superfície da fatia; H denota todos os hidrogênios ligados à molécula de estireno;

- C_B denota um átomo de carbono pertencente ao anel da molécula, conectado a dois carbonos e um hidrogênio;

- C_A faz ligação somente com carbonos e possui carga nula;

- C_12 possui vizinhança de dois carbonos e dois hidrogênios;

- C_13 denota o átomo de carbono da molécula ligado ao átomo Si_C.

- C_13m utilizamos esta nomenclatura em nosso campo, pois para a molécula isolada este átomo difere pela vizinhança do carbono 13 da superfície funcionalizada.

Na tabela 3.4 apresentamos também os valores das cargas UFFN adotadas para os tipos atômicos que utilizamos em nosso campo. A diferença entre os valores listados com os de Hirshfeld (obtidos diretamente do FHI-AIMS) mostra os ajustes necessários para manter a neutralidade de carga do sistema, que são mais significativas apenas para os tipos atômicos $\mathrm{C}_{-} 12$ e H.

Os parâmetros de LJ foram obtidos através de cálculos ab initio, realizados utilizando o código computacional FHI-AIMS [39] conforme indicado no capítulo anterior. A tabela 3.5 mostra os parâmetros de LJ para os tipos atômicos utilizados no UFFN, que estão comparados aos valores originais do UFF [27].

As Figuras 3.5(a), 3.5(b) e 3.5(c) mostram as curvas para o potencial de LJ dos tipos atômicos presentes em nosso campo e comparados ao UFF. Notamos que o potencial de LJ para o átomo de H de superfície é mais repulsivo que aquele ligado 


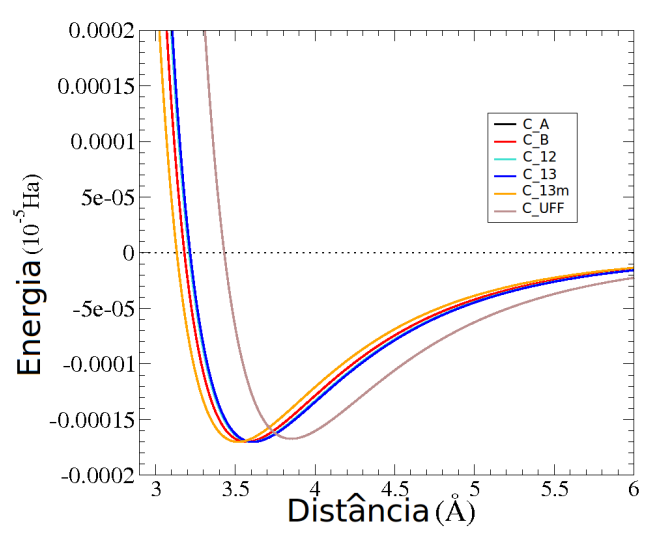

(a) Carbonos

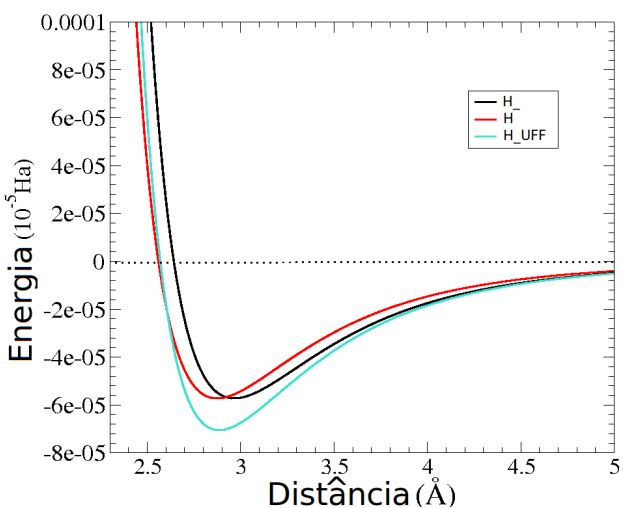

(b) Hidrogênios

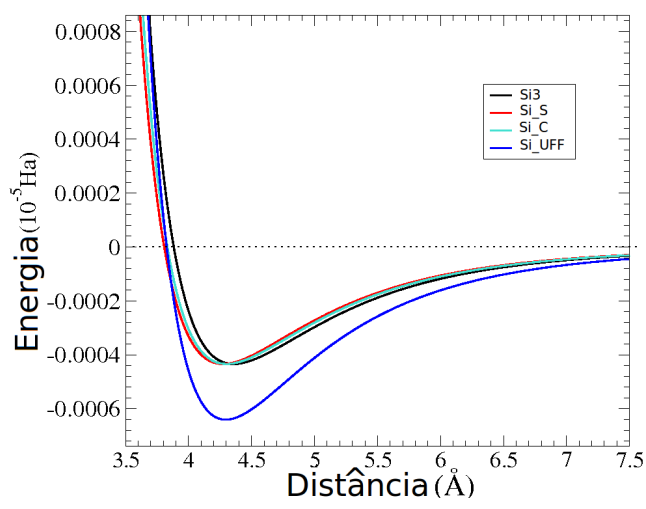

(c) Silícios

Figura 3.5: Potencial de Lennard-Jones dos diferentes tipos atômicos presentes no UFFN. Em (a), tipos atômicos atribuídos ao carbono. Em (b), tipos atômicos atribuídos ao hidrogênio. Em (c), tipos atômicos atribuídos ao silício.

aos átomos de C, conforme esperado. Tendência semelhante também é obtida para o Si: os átomos de superfície exibem os menores valores de $\mathrm{r}_{I J}$. Para $\mathrm{C}$, todos os valores de $\mathrm{r}_{I J}$ são muito próximos.

\subsubsection{Molécula Isolada}

Com os parâmetros descritos até aqui, definimos um campo, UFFN, com os parâmetros de LJ baseados na carga de Hirshfeld para todos os tipos atômicos de interesse neste trabalho. Verificamos agora com este campo, a descrição dos parâmetros 
estruturais da molécula isolada de estireno (Figura 3.1). Os resultados obtidos estão mostrados na tabela 3.6 e podem ser comparados aos valores calculados com o UFF utilizando Qeq $\left(\mathrm{UFF}_{c}\right)$, e PCFF (com cargas atribuídas por este campo). Notemos que os parâmetros estruturais são bem descritos com todos os campos de força. Existe um desacordo entre os resultados clássicos obtidos com $\mathrm{UFF}_{c}$ e PCFF e nossos resultados DFT apenas para o ângulo diedral (C4-C3-C12-C13). Comparativamente, o UFFN reproduz os resultados dos cálculos de primeiros princípios e também está em acordo com as simulações utilizando MP2 [51].

\subsubsection{Superfícies de Si Hidrogenadas}

Iniciaremos nossas discussões formalizando os parâmetros estruturais obtidos para as superfícies $\operatorname{Si}(100)(2 x 1): H, \operatorname{Si}(100)(1 x 1): 2 H$ e $\operatorname{Si}(100)(3 x 1): H$, via cálculos de otimização de geometria, utilizando os campos de força UFFN e UFF (com carga nula) para comparação. No capítulo 1 (Figura 3.3) já definimos a etiqueta utilizada para descrição dos parâmetros estruturais listados nas tabelas 3.7, 3.8 e 3.9 para as superfícies citadas.

O parâmetro de rede lateral das fatias foi obtido em cada caso a partir do parâmetro de rede otimizado para o silício bulk com os respectivos campos. Otimizamos fatias contendo 8, 10, 12, 20 e 60 camadas de Si. Notamos que os resultados estavam convergidos com uma fatia contendo 10 camadas. Os resultados mais importantes para as três superfícies são resumidos nas tabelas 3.7, 3.8, 3.9 e 3.10.

Como pode ser visto na comparação entre os erros percentuais dos cálculos utilizando UFFN e UFF em relação a resultados teóricos/experimentais, obtemos com nossa parametrização melhora significativa na descrição das propriedades estruturais destas superfícies. Notemos que em nenhum dos casos os erros obtidos com UFFN são maiores do que aqueles obtidos com o UFF.

Como um exemplo adicional das modificações introduzidas por nossa reparametrização, mostramos na Figura 3.6 uma comparação entre as estruturas otimizadas da 
superfície $\operatorname{Si}(100)(1 \times 1): 2 \mathrm{H}$ com ambos os campos de força (UFF e UFFN). Fica

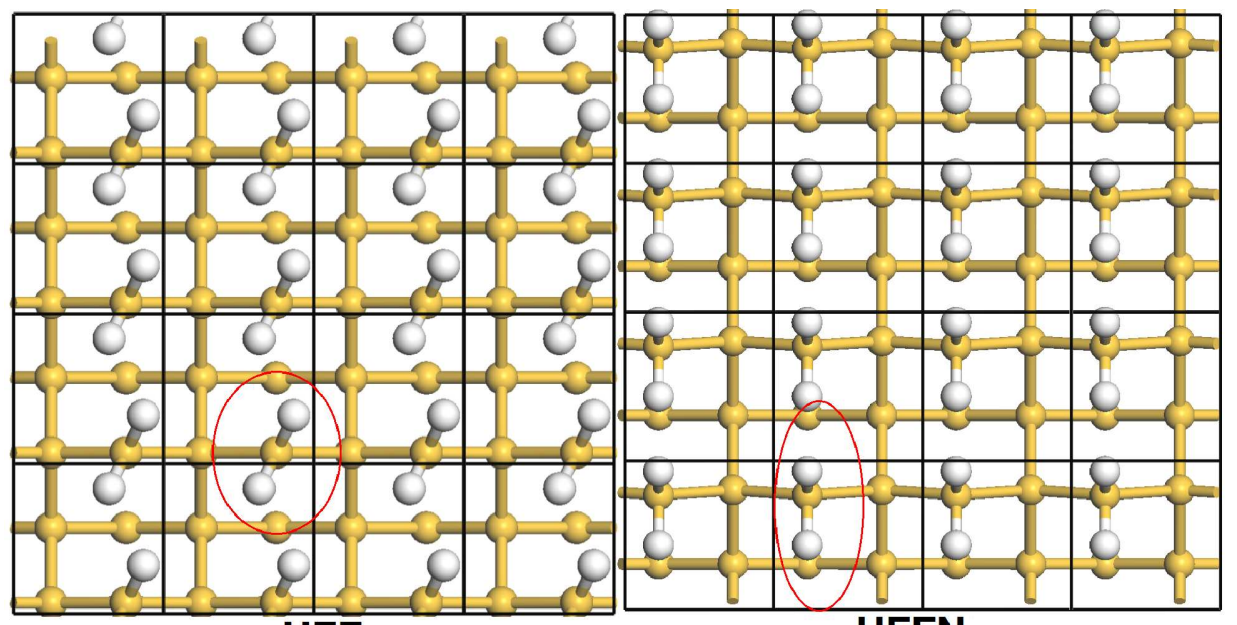

UFF

UFFN

Figura 3.6: Comparação entre as estruturas otimizadas com o UFF e UFFN para a superfície $\operatorname{Si}(100)(1 \times 1): 2 H$.

clara a mudança no posicionamento do grupo de superfície $\mathrm{SiH}_{2}$ (região delimitada). Como um teste adicional, otimizamos também a geometria da superfície cortada em direção diferente, e para qual adotamos uma célula primitiva (1x1). O átomo de Si identificado como 1 corresponde ao tipo atômico $\mathrm{Si}_{-} S$. Os parâmetros estruturais para a $\operatorname{Si}(111)(1 \times 1): H$ estão mostrados na tabela 3.11. Para essa superfície, o UFF introduz erros nos parâmetros estruturais da ordem de $\approx 6 \%$, enquanto todos os nossos erros são menores que $1 \%$. 
Tabela 3.1: Distâncias Si-Si $(\AA)$, ângulos Si-Si-Si $\left(^{0}\right)$, parâmetro de rede $a_{0}(\AA)$, e módulo de compressibilidade B (GPa) do cristal de silício. São incluídos valores experimentais, resultados teóricos da literatura, e nossos resultados (DFT/PBE); os resultados com mecânica molecular foram calculados com os campos de força indicados. Os cálculos no UFF foram realizados sem carga atômica e as cargas utilizadas no PCFF foram atribuídas pelo próprio campo.

\begin{tabular}{lccc|ccc}
\hline \hline & Expt. [1,48] & DFT/PZ [6] & DFT/PBE & UFF & PCFF & UFFN \\
\hline Si-Si & 2,350 & 2,350 & 2,377 & 2,217 & 2,344 & 2,355 \\
Si-Si-Si & 109,470 & 109,500 & 109,471 & 109,471 & 109,471 & 109,471 \\
$\mathrm{a}_{0}$ & 5,431 & 5,398 & 5,470 & 5,120 & 5,414 & 5,445 \\
$\mathrm{~B}$ & 90 & 81,15 & - & 108,878 & 109,036 & 94,703 \\
\hline \hline
\end{tabular}


Tabela 3.2: Cargas atômicas para molécula isolada de estireno (Figura 3.1). O índice "c" significa que utilizamos o método Qeq para calcular as cargas nas otimizações de geometria, com os campos de força. As cargas de Lowdin foram calculadas utilizando o pacote ESPRESSO e as de Hirshfeld com o código FHI-AIMS.

\begin{tabular}{lcc|cc}
\hline \hline Átomos & Lowdin & Hirshfeld & $\mathrm{UFF}_{c}$ & $\mathrm{PCFF}_{c}$ \\
\hline C1 & $-0,103$ & $-0,046$ & $-0,113$ & $-0,112$ \\
C2 & $-0,107$ & $-0,043$ & $-0,095$ & $-0,094$ \\
C3 & 0,052 & $\mathbf{- 0 , 0 0 3}$ & 0,064 & 0,060 \\
C4 & $-0,103$ & $-0,041$ & $-0,078$ & $-0,076$ \\
C5 & $-0,100$ & $-0,045$ & $-0,117$ & $-0,115$ \\
C6 & $-0,106$ & $-0,046$ & $-0,105$ & $-0,103$ \\
H7 & 0,178 & 0,047 & 0,103 & 0,100 \\
H8 & 0,169 & 0,045 & 0,092 & 0,091 \\
H9 & 0,166 & 0,045 & 0,098 & 0,096 \\
H10 & 0,177 & 0,047 & 0,101 & 0,099 \\
H11 & 0,178 & 0,047 & 0,104 & 0,102 \\
C12 & $-0,090$ & $-0,043$ & $-0,139$ & $-0,135$ \\
C13 & $-0,279$ & $\mathbf{- 0 , 0 9 4}$ & $-0,301$ & $-0,294$ \\
H14 & 0,165 & 0,043 & 0,122 & 0,121 \\
H15 & 0,163 & 0,041 & 0,135 & 0,130 \\
H16 & 0,184 & 0,044 & 0,130 & 0,127 \\
\hline \hline
\end{tabular}


Tabela 3.3: Cargas atômicas para superfície de $\operatorname{Si}(100)(2 x 1): H$ (10 camadas) (Figura 3.3 (a)). O indice "c" significa que utilizamos o método Qeq para calcular as cargas nas otimizações de geometria com o UFF. No PCFF foram utilizadas as cargas internas. As cargas de Lowdin foram calculadas utilizando o pacote ESPRESSO e as de Hirshfeld com o código FHI-AIMS.

\begin{tabular}{lccc|c}
\hline \hline $\mathrm{Si}(100)(2 \mathrm{x} 1): \mathrm{H}$ & Lowdin & Hirshfeld & $\mathrm{UFF}_{c}$ & PCFF \\
\hline Si_S & 0,115 & 0,065 & 0,052 & 0,126 \\
$\mathrm{Si} 3$ & 0,022 & $-0,001$ & 0,000 & 0,000 \\
$\mathrm{Si} 6$ & 0,049 & 0,009 & $-0,007$ & 0,000 \\
$\mathrm{Si} 7$ & 0,038 & 0,003 & $-0,003$ & 0,000 \\
$\mathrm{H} 1$ & $-0,035$ & $-0,066$ & $-0,037$ & $-0,126$ \\
\hline \hline
\end{tabular}


Tabela 3.4: Molécula de estireno quimissorvida sobre silício (as etiquetas utilizadas estão definidas na Figura 3.4). A definição dos tipos atômicos listados é discutida em detalhes na seção 3.3. Cargas atribuídas aos tipos atômicos utilizados em UFFN (Figura 3.4). As definições dos tipos atômicos listados é discutida em detalhes no texto.

\begin{tabular}{lc|lc}
\hline \hline Tipos atômicos & Molécula & Tipos atômicos & Fatia \\
\hline H & 0,0366 & H_ & $-0,0644$ \\
C_A & 0,0075 & Si_C & 0,1093 \\
C_12 & $-0,0681$ & Si_S & 0,0644 \\
C_13 & $-0,1440$ & Si3 & 0,0008 \\
C_B & $-0,0452$ & & \\
\hline \hline Tipos atômicos & UFFN & Tipos atômicos & UFFN \\
\hline H & 0,045 & H_ & $-0,064$ \\
C_A & 0,000 & Si_C & 0,109 \\
C_12 & $-0,090$ & Si_S & 0,064 \\
C_13 & $-0,199$ & Si3 & 0,000 \\
C_B & $-0,045$ & & \\
\hline \hline
\end{tabular}


Tabela 3.5: Parâmetros de LJ para os tipos atômicos presentes no UFFN. Os parâmetros de LJ de C_13m, utilizados para molécula isolada também estão dispostos na tabela. Utilizamos esta nomenclatura em nosso campo, pois para a molécula isolada este átomo difere pela vizinhança do carbono 13 da superfície funcionalizada. Os parâmetros para o $\mathrm{Si}, \mathrm{C}$ e H presentes no UFF foram denotados por $\mathrm{Si}_{U F F}, \mathrm{C}_{U F F}$ e $\mathrm{H}_{U F F}$ respectivamente.

\begin{tabular}{|c|c|c|c|}
\hline Tipo atômico & $\mathrm{r}_{I J}(\AA)$ & $\mathrm{D}_{0}(\mathrm{kcal} / \mathrm{mol})$ & C6 $\left(\right.$ Ha.Bohr $\left.{ }^{6}\right)$ \\
\hline$C_{-} B$ & 3,571 & 0,107 & 32,2 \\
\hline $\mathrm{C}_{-} A$ & 3,609 & 0,107 & 34,2 \\
\hline$C_{-} 12$ & 3,604 & 0,107 & 33,9 \\
\hline $\mathrm{C}_{-} 13$ & 3,611 & 0,107 & 34,4 \\
\hline C_ $13 m$ & 3,517 & 0,107 & 29,3 \\
\hline $\mathrm{H}$ & 2,873 & 0.036 & 2,9 \\
\hline $\mathrm{H}_{-}$ & 2,966 & 0.036 & 3,5 \\
\hline $\mathrm{Si}_{-} C$ & 4,301 & 0,272 & 250,3 \\
\hline $\mathrm{Si} \_S$ & 4,273 & 0,272 & 240,8 \\
\hline $\mathrm{Si} 3$ & 4,358 & 0,272 & 270,9 \\
\hline $\mathrm{Si}_{U F F}$ & 4,295 & 0,402 & 366,3 \\
\hline $\mathrm{H}_{U F F}$ & 2,886 & 0,044 & 3,7 \\
\hline $\mathrm{C}_{U F F}$ & 3,851 & 0,105 & 49,7 \\
\hline
\end{tabular}


Tabela 3.6: Parâmetros estruturais da molécula de estireno. PBE-PW-US se refere aos cálculos realizados utilizando o método de ondas planas e com pseudopotencias utra-soft. O índice "c" em UFF denota os cálculos realizados com Qeq. A etiqueta utilizada na tabela está definida na Figura 3.1.

\begin{tabular}{lc|rcc}
\hline \hline & PBE/PW-US & $\mathrm{UFF}_{c}$ & $\mathrm{PCFF}$ & $\mathrm{UFFN}$ \\
Distâncias $(\AA)$ & & & & \\
\hline C1-C2 & 1,40 & 1,40 & 1,39 & 1,39 \\
C2-C3 & 1,41 & 1,40 & 1,42 & 1,39 \\
C3-C4 & 1,41 & 1,41 & 1,41 & 1,39 \\
C4-C5 & 1,39 & 1,40 & 1,39 & 1,39 \\
C5-C6 & 1,40 & 1,40 & 1,40 & 1,39 \\
C6-C1 & 1,40 & 1,40 & 1,40 & 1,39 \\
C3-C12 & 1,47 & 1,48 & 1,51 & 1,47 \\
C12-C13 & 1,34 & 1,34 & 1,35 & 1,35 \\
\hline Angulos $\left({ }^{0}\right)$ & & & & \\
C1-C6-C5 & 119,42 & 119,98 & 119,68 & 119,96 \\
C2-C3-C4 & 117,94 & 118,84 & 117,70 & 119,39 \\
C3-C4-C5 & 120,91 & 120,38 & 121,25 & 120,18 \\
C3-C12-C13 & 127,63 & 124,08 & 124,05 & 121,26 \\
C4-C3-C12-C13 & 1,29 & 21,08 & 21,29 & $\mathbf{0 , 0 2}$ \\
\hline \hline
\end{tabular}


Tabela 3.7: Parâmetros estruturais da $\mathrm{Si}(100)(2 \mathrm{x} 1): \mathrm{H}$ obtidos com o UFF (U) (com cargas nula) [26] e nossa versão parametrizada deste campo, o UFFN (UN). Na tabela temos as diferenças percentuais dos parâmetros obtidos com estes campos relativos a resultados LDA (L) da literatura [6] e experimentais (E) [52]. As etiquetas da tabela estão definidas na Figura 3.3.

\begin{tabular}{lcccccccc}
\hline \hline Átomos & \multirow{2}{*}{$\mathrm{E}$} & $\mathrm{L}$ & $\mathrm{U}$ & $\mathrm{UN}$ & $\mathrm{U}-\mathrm{L}$ & $\mathrm{UN}-\mathrm{L}$ & $\mathrm{U}-\mathrm{E}$ & $\mathrm{U}$ UN-E \\
Distâncias $(\AA)$ & & & & & $\%$ & $\%$ & $\%$ & $\%$ \\
\hline H1-H2 & 3,44 & 3,44 & 3,49 & 3,46 & 1,44 & 0,60 & 1,46 & 0,61 \\
H1-Si1 & 1,51 & 1,50 & 1,47 & 1,47 & $-2,10$ & $-2,03$ & $-2,73$ & $-2,68$ \\
Si1-Si2 & 2,45 & 2,38 & 2,29 & 2,30 & $-3,78$ & $-3,53$ & $-6,53$ & $-6,29$ \\
Si1-Si3 & 2,36 & 2,34 & 2,23 & 2,37 & $-4,63$ & 1,47 & $-5,44$ & 0,61 \\
Si3-Si5 & 2,36 & 2,34 & 2,19 & 2,32 & $-6,22$ & $-0,76$ & $-7,01$ & $-1,60$ \\
Si3-Si6 & 2,40 & 2,36 & 2,26 & 2,43 & $-4,15$ & 2,81 & $-5,74$ & 1,10 \\
Si5-Si9 & 2,33 & 2,33 & 2,20 & 2,33 & $-5,76$ & $-0,09$ & $-5,76$ & $-0,09$ \\
Si7-Si8 & 2,37 & 2,35 & 2,25 & 2,37 & $-4,06$ & 1,06 & $-4,87$ & 0,21 \\
\hline Ângulos $\left({ }^{0}\right)$ & & & & & $\%$ & $\%$ & & \\
H1-Si1-Si2 & - & 110,90 & 114,08 & 113,37 & 2,87 & 2,23 & - & - \\
Si3-Si1-Si2 & - & 105,26 & 104,15 & 105,09 & $-1,05$ & $-0,17$ & - & - \\
Si3-Si5-Si4 & - & 100,00 & 100,48 & 99,01 & 0,48 & $-0,99$ & - & - \\
Si6-Si3-Si5 & - & 113,28 & 107,65 & 108,74 & $-4,97$ & $-4,00$ & - & - \\
Si3-Si6-Si7 & - & 107,00 & 108,01 & 107,62 & 0,94 & $-0,36$ & - & - \\
\hline \hline
\end{tabular}


Tabela 3.8: Parâmetros estruturais da Si(100)(1x1):2H obtidos com o UFF (U) (com carga nula) [26] e nossa versão parametrizada deste campo, o UFFN (UN). Na tabela temos as diferenças percentuais dos parâmetros obtidos com estes campos relativos à resultados LDA (L) [6]. A etiqueta da tabela está definida na Figura 3.3.

\begin{tabular}{lccccc}
\hline \hline Átomos & $\mathrm{L}$ & $\mathrm{U}$ & $\mathrm{UN}$ & $\begin{array}{c}\text { U-L } \\
\text { UN-L }\end{array}$ & $\begin{array}{c}\text { UN } \\
\text { Distâncias }(\AA)\end{array}$ \\
\hline H1-H1 & 2,38 & 1,95 & 2,06 & $-17,20$ & $-13,38$ \\
H1-Si1 & 1,51 & 1,45 & 1,47 & $-4,00$ & $-2,51$ \\
H2-Si1 & 1,49 & 1,45 & 1,41 & $-3,10$ & $-5,48$ \\
Si1-Si2 & 2,33 & 2,22 & 2,35 & $-4,50$ & 1,15 \\
Si2-S3 & 2,34 & 2,22 & 2,37 & $-4,93$ & 1,35 \\
Si3-Si4 & 2,34 & 2,22 & 2,36 & $-5,18$ & 0,73 \\
Si4-Si5 & 2,34 & 2,22 & 2,36 & $-5,24$ & 0,78 \\
\hline Ângulos $\left({ }^{0}\right)$ & & & & $\%$ & $\%$ \\
H1-Si1-H2 & 105,25 & 85,01 & 91,59 & $-19,23$ & $-12,99$ \\
Si1-Si2-Si3 & 116,32 & 109,71 & 112,07 & $-5,68$ & $-3,65$ \\
Si2-Si3-Si4 & 108,25 & 109,60 & 109,52 & 1,25 & 1,18 \\
Si3-Si4-Si5 & 110,30 & 109,56 & 109,45 & $-0,67$ & $-0,77$ \\
\hline \hline
\end{tabular}


Tabela 3.9: Parâmetros estruturais da $\operatorname{Si}(100)(3 \times 1): H$ obtidos com o UFF (U) (com carga nula) [26] e nossa versão parametrizada deste campo, o UFFN (UN). Na tabela temos as diferenças percentuais dos parâmetros obtidos com estes campos relativos à resultados LDA (L) [6]. A etiqueta da tabela está definida na Figura 3.3.

\begin{tabular}{lccccc}
\hline \hline Átomos & $\mathrm{L}$ & $\mathrm{U}$ & $\mathrm{UN}$ & $\mathrm{U}-\mathrm{L}$ & $\mathrm{UN}-\mathrm{L}$ \\
Distâncias $(\AA)$ & & & & $\%$ & $\%$ \\
\hline H1-H2 & 3,45 & 3,45 & 3,46 & 0,08 & 0,29 \\
H2-H3 & 2,86 & 2,49 & 2,77 & $-12,91$ & $-3,05$ \\
H3-H4 & 2,43 & 2,40 & 2,41 & $-1,56$ & $-1,05$ \\
H1-Si1 & 1,50 & 1,47 & 1,47 & $-2,12$ & $-2,00$ \\
Si1-Si2 & 2,40 & 2,28 & 2,29 & $-4,83$ & $-4,46$ \\
Si2-S4 & 2,34 & 2,23 & 2,37 & $-4,67$ & 1,40 \\
Si4-Si5 & 2,32 & 2,18 & 2,29 & $-6,06$ & $-1,07$ \\
Si3-Si6 & 2,37 & 2,26 & 2,42 & $-4,52$ & 2,06 \\
Si6-Si7 & 2,36 & 2,23 & 2,37 & $-5,51$ & 0,47 \\
Si7-Si8 & 2,37 & 2,21 & 2,35 & $-6,72$ & $-0,90$ \\
Si8-Si9 & 2,31 & 2,18 & 2,31 & $-5,61$ & $-0,08$ \\
Si13-Si14 & 2,33 & 2,22 & 2,36 & $-4,58$ & 1,38 \\
\hline \hline
\end{tabular}


Tabela 3.10: Continuação - Parâmetros estruturais da Si(100)(3x1):H (Figura 3.3) obtidos com o UFF (U) (com carga nula) [26] e uma versão parametrizada deste campo, o UFFN (UN). Na tabela temos as diferenças percentuais dos parâmetros obtidos com estes campos relativos à resultados LDA (L) [6]. A etiqueta da tabela está definida na Figura 3.3.

\begin{tabular}{lccccc}
\hline \hline $\begin{array}{l}\text { Átomos } \\
\text { Ângulos }\left({ }^{0}\right)\end{array}$ & $\mathrm{L}$ & $\mathrm{U}$ & $\mathrm{UN}$ & $\begin{array}{c}\text { U-L } \\
\%\end{array}$ & $\begin{array}{c}\text { UN-L } \\
\%\end{array}$ \\
\hline H1-Si1-Si2 & 110,46 & 113,69 & 113,49 & 2,92 & 2,74 \\
H3-Si14-H4 & 108,44 & 109,47 & 110,12 & 0,95 & 1,55 \\
Si1Si2-Si4 & 104,92 & 104,07 & 104,90 & $-0,81$ & $-0,02$ \\
Si2-Si4-Si5 & 97,21 & 98,91 & 98,46 & 1,75 & 1,28 \\
Si4-Si5-Si3 & 101,70 & 100,50 & 99,15 & $-1,18$ & $-2,51$ \\
Si3-Si6-Si7 & 107,66 & 108,60 & 108,23 & 0,87 & 0,53 \\
Si6-Si7-Si8 & 109,50 & 109,04 & 109,06 & $-0,42$ & $-0,40$ \\
Si7-Si8-Si9 & 113,50 & 113,08 & 113,18 & $-0,37$ & $-0,28$ \\
Si4-Si5-Si9 & 110,78 & 110,83 & 110,93 & 0,05 & 0,14 \\
Si4-Si12-Si13 & 109,84 & 111,31 & 111,97 & 1,34 & 1,94 \\
Si12-Si13-Si14 & 107,90 & 109,69 & 109,33 & 1,66 & 1,32 \\
\hline \hline
\end{tabular}


Tabela 3.11: Parâmetros estruturais da Si(111)(1x1):H obtidos com o UFF (com carga nula) (U) [26] e nossa versão parametrizada deste campo, o UFFN (UN). Na tabela temos as diferenças percentuais dos parâmetros obtidos com estes campos relativos à resultados LDA (L) [6]. A etiqueta da tabela está definida na Figura 3.2.

\begin{tabular}{lccccc}
\hline \hline & L & U & UN & $\begin{array}{c}\text { U-L } \\
\%\end{array}$ & $\begin{array}{c}\text { UN-L } \\
\text { Distâncias }(\AA)\end{array}$ \\
\hline H-Si1 & 1,503 & 1,469 & 1,470 & $-2,237$ & $-0,033$ \\
Si1-Si2 & 2,338 & 2,310 & 2,355 & $-1,184$ & 0,741 \\
Si2-Si3 & 2,335 & 2,224 & 2,357 & $-4,735$ & 0,962 \\
Si3-Si4 & 2,345 & 2,312 & 2,352 & $-1,393$ & 0,313 \\
Si4-Si5 & 2,354 & 2,219 & 2,353 & $-5,744$ & $-0,052$ \\
\hline Ângulos $\left({ }^{0}\right)$ & & & & $\%$ & $\%$ \\
H-Si1-Si2 & 108,758 & 106,300 & 109,700 & $-2,260$ & 0,866 \\
Si1-Si2-Si3 & 108,754 & 106,300 & 109,700 & $-2,256$ & 0,870 \\
Si2-Si3-Si4 & 109,360 & 106,500 & 109,500 & $-2,615$ & 0,128 \\
Si3-Si4-Si5 & 109,430 & 106,500 & 109,500 & $-2,677$ & 0,064 \\
\hline \hline
\end{tabular}




\subsection{Reflexos nas Propriedades Eletrônicas}

Verificamos a seguir o impacto de nossa parametrização na descrição das propriedades eletrônicas do silício cristalino e da $\operatorname{Si}(100)(2 \times 1): H$, discutindo quais mudanças são observadas na estrutura de bandas e densidade de estados (DOS) do Si bulk e da superfície $\operatorname{Si}(100)(2 \times 1): H$ quando utilizamos a geometria otimizada com os campos de força UFFN e UFF. Os resultados obtidos com estes campos de força também serão comparados a resultados DFT/PBE obtidos com o código ESPRESSO [40] detalhados na seção 3.1. Conforme veremos, a correta descrição estrutural é fundamental para que possamos ter uma análise confiável das propriedades eletrônicas dos sistemas investigados neste trabalho.

A tabela 3.12 mostra os valores de gap obtidos para o cristal de Si e superfície Si(100)(2x1):H. Os cálculos foram realizados partindo de configurações com posições

Tabela 3.12: Gaps estimados da diferença entre as energias do HOMO e LUMO para o Si bulk e Si(100)(2x1):H. Os cálculos foram realizados partindo configurações otimizadas com UFFN e UFF. Temos também o gap obtido de um cálculo DFT/PBE otimizando as coordenadas atômicas e a célula unitária.

\begin{tabular}{l|cccc}
\hline \hline & Expt & UFF & UFFN & DFT/PBE \\
\hline Gap (eV) - Si bulk & $1,13[53]$ & 0,289 & 0,666 & 0,658 \\
Gap (eV) - Si $(100)(2 \times 1): H$ & - & 0,675 & 0,941 & 0,930 \\
\hline \hline
\end{tabular}

atômicas e célula unitária relaxadas através do UFFN, UFF e DFT/PW/PBE. Em nossos cálculos sempre utilizamos células primitivas construídas com os respectivos parâmetros de rede $\left(\mathrm{a}_{0}\right)$ listados na tabela 3.1 .

Nas Figuras 3.7(a) e 3.7(b) apresentamos a DOS e a estrutura de bandas do Si obtidas para o cristal de Si utilizando a estrutura geometrica obtida com os campos de força UFFN e UFF. Inserimos, em ambos os casos, os resultados obtidos a partir de um cálculo de primeiros princípios utilizando estrutura otimizada com DFT/PBE. 
Nestes gráficos, a energia do topo da banda de valência (TBV) do cristal é tomada como referência $(0 \mathrm{eV})$, de modo que valores de energia negativos estejam associados a estados eletrônicos ocupados.

Na região do gap, o desacordo é pronunciado nos pontos X-W-L para a banda de valência e L-G na banda de condução. O gap, conforme esperado, é indireto, tanto para a estrutura previamente otimizada (parâmetro de rede e posições atômicas, tabela 3.1) com o UFF quanto com o UFFN. É amplamente conhecido pela comunidade científica que a DFT é uma teoria de estado fundamental e fornece valores subestimados para o gap do Si. Entretanto, chamamos a atenção para o fato de que o valor do gap calculado com UFF e o UFFN diferem de $56,1 \%$ e 1,2 \% do resultado DFT/PBE (tabela 3.12, Figuras 3.7(a) e 3.7(b)). Portanto, ao utilizarmos a geometria oriunda de UFFN dimuinuímos o erro cometido no gap de 32,2 \% em relação ao resultado do UFF, quando ambos são confrontados ao resultado experimental.

Além da região do gap, notamos que uma boa descrição no parâmetro de rede também influência na largura da banda de valência do cristal. Notamos, nas Figuras 3.7(a) e 3.7(b), que a banda obtida a partir da geometria UFF tem uma largura maior que aquela calculada com o UFFN, quando comparamos os nossos dados com o obtido dos cálculos de primeiros princípios.

Passemos agora à análise da DOS mostrada na Figura 3.8, para a superfície $\operatorname{Si}(100)(2 x 1)$ :H. A DOS foi obtida a partir da geometria otimizada com o UFFN e UFF. As diferenças identificadas na DOS são muito semelhantes às observadas para o cristal de Si, quando confrotamos os resultados para os dois campos de força. Observamos que o gap calculado para a superfície oriunda de UFFN é 39,4 \% maior que o gap proveniente do UFF. Também identificamos que a largura da banda de valência (resultado não mostrado) é diferente se o cálculo é realizado com a geometria proveniente de um ou outro campo de força. De forma geral o UFFN fornece uma geometria confiável o bastante para que se possa fazer um estudo detalhado das propriedades eletrônicas da molécula de estireno quimissorvida na superfície. 


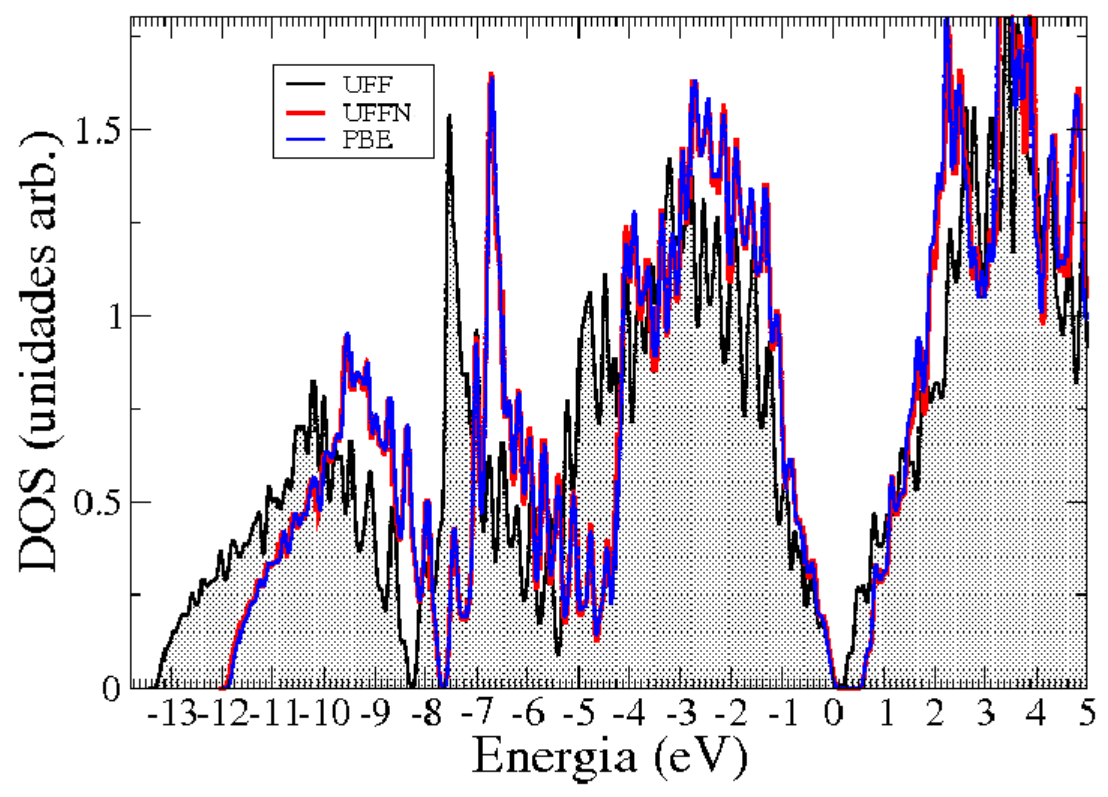

(a) DOS
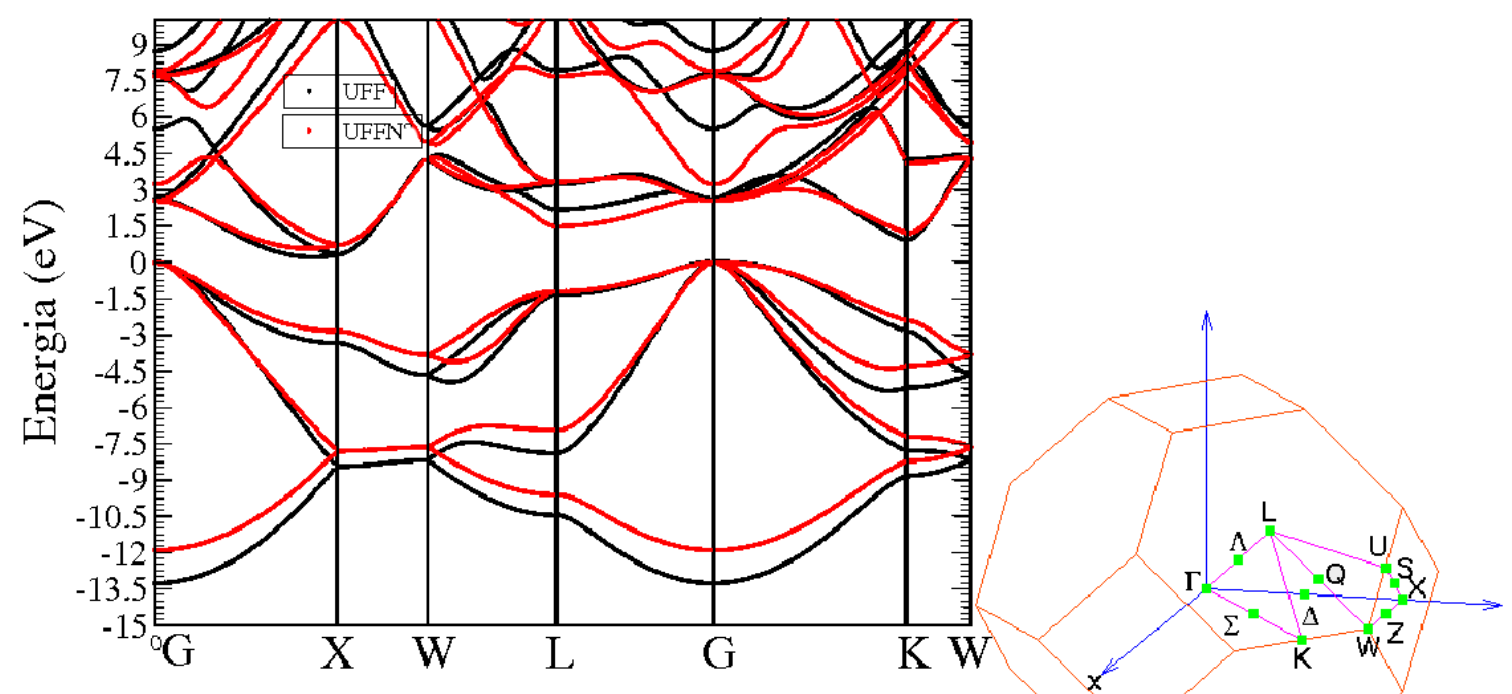

(b) Estrutura de Bandas

Figura 3.7: Em (a), Densidades de Estados do cristal de Si obtidas de estruturas inicialmente otimizadas com UFFN e UFF. Aquela DOS obtida de um cálculo totalmente ab initio (DFT/PBE) também é mostrada na figura. Em (b), Estrutura de bandas do cristal de Si e pontos de alta simetria da Zona de Brilouin (BZ). 


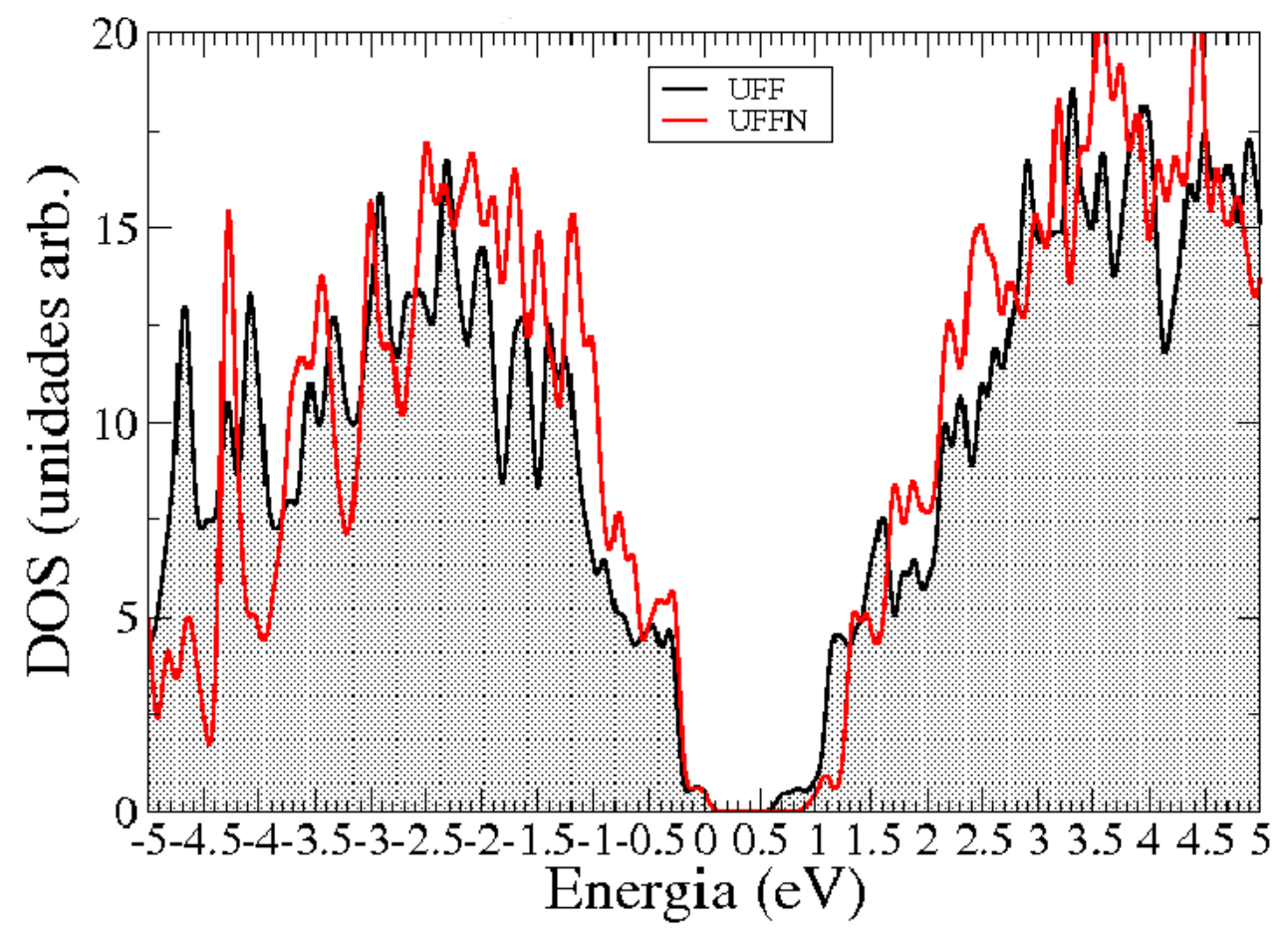

Figura 3.8: Densidades de Estados da $\operatorname{Si}(100)(2 \mathrm{x} 1): \mathrm{H}$ obtidas de estruturas inicialmente otimizadas com UFFN e UFF. 


\section{Capítulo 4}

\section{Estudo de monocamadas de estireno sobre $\operatorname{Si}(100)(2 \times 1): H$}

Neste capítulo simulamos o comportamento da molécula de estireno sobre a superfície $\operatorname{Si}(100)(2 x 1): H$, utilizando Dinâmica Molecular Clássica. Fizemos estudo da molécula fisissorvida e quimissorvida sobre a superfície utilizando o nosso campo reparametrizado UFFN, e em alguns casos incluímos resultados obtidos com UFF (com carga nula) e PCFF (com cargas internas) para comparação.

\subsection{Moléculas de Estireno Fisissorvidas}

\section{Deposição de Moléculas de Estireno}

Investigamos a deposição de moléculas de estireno sobre a superfície $\mathrm{Si}(100)(2 \mathrm{x} 1): \mathrm{H}$ utilizando uma supercélula 8x6, baseada em simulações de Dinâmica Molecular Clássica com UFFN e UFF [54], para comparação. Não utilizamos o Qeq para atribuição de cargas atômicas no UFF. Neste caso, as interações de longo alcance são exclusivamente de van der Waals. Nos cálculos de DMI, utilizamos o ensemble NVE (seção 2.1) e os cálculos foram realizados a $300 \mathrm{~K}$. A velocidade inicial atribuída à molécula de estireno foi de $218 \mathrm{~cm} / \mathrm{s}$ em direção à superfície e a distância na qual 
as moléculas foram lançadas foi de $15 \AA$. O tempo total de simulação foi de 20 ps, com as equações de Verlet sendo integradas a cada 1 fs. Os parâmetros de rede relativos à periodicidade bidimensional da superfície foram tomados do parâmetro de rede calculado para o Si bulk (tabela 3.1) com o UFFN e UFF. Para direção a $\boldsymbol{z}$, empregamos $\mathrm{c}=100,00 \AA$ para prevenir a interação entre imagens periódicas da superfície. Como os campos de força utilizados neste trabalho são não reativos, para a simulação de DMI estamos investigando os processos de fisissorção da molécula sobre a superfície do semicondutor.

Iniciaremos as discussões com a deposição de uma única molécula sobre a superfície monohidrogenada. A molécula de estireno foi lançada de 6 configurações iniciais distintas e sempre em direção à superfície. Não identificamos qualquer influência da posição inicial da simulação na interação entre a molécula e a superfície. Esta afirmativa se aplica tanto ao UFFN quanto ao UFF. Para UFFN, observamos que o anel aromático (grupo fenil) interage preferencialmente com a região de vale da superfície enquanto há uma tendência de interação entre grupo vinil e dímeros pristinos. Este comportamento se torna bastante evidente quando, durante o período de simulação, a molécula se desloca entre os vales. A Figura 4.1 mostra fotografias para duas conformações da molécula fisissorvida sobre a superfície monohidrogenada, decorrido o tempo total de simulação com o UFFN. Denominamos estas estruturas de $a$ e $b$. Em ambos os casos, observamos estruturas resultantes da molécula de estireno "atraída" pela região de vale da superfície. A conformação a ilustra bem o que ocorre durante a DMI: nota-se que o vale é uma região preferencial de "acomodação" da molécula. Esta tendência se confirma ao longo das 6 simulações feitas com UFFN. Na conformação $b$, observamos uma outra possível situação na qual a molécula também termina sobre a região de vale, mas com a atração ocorrendo através do grupo vinil. Para os 6 diferentes casos analisados, em apenas um, o estireno estabiliza sobre os dímeros. No entanto, durante boa parte da simulação, a molécula ainda fica "presa" nas regiões de vale. A distância entre os carbonos e os átomos de silício de superfície são próximas de $4 \AA$. 


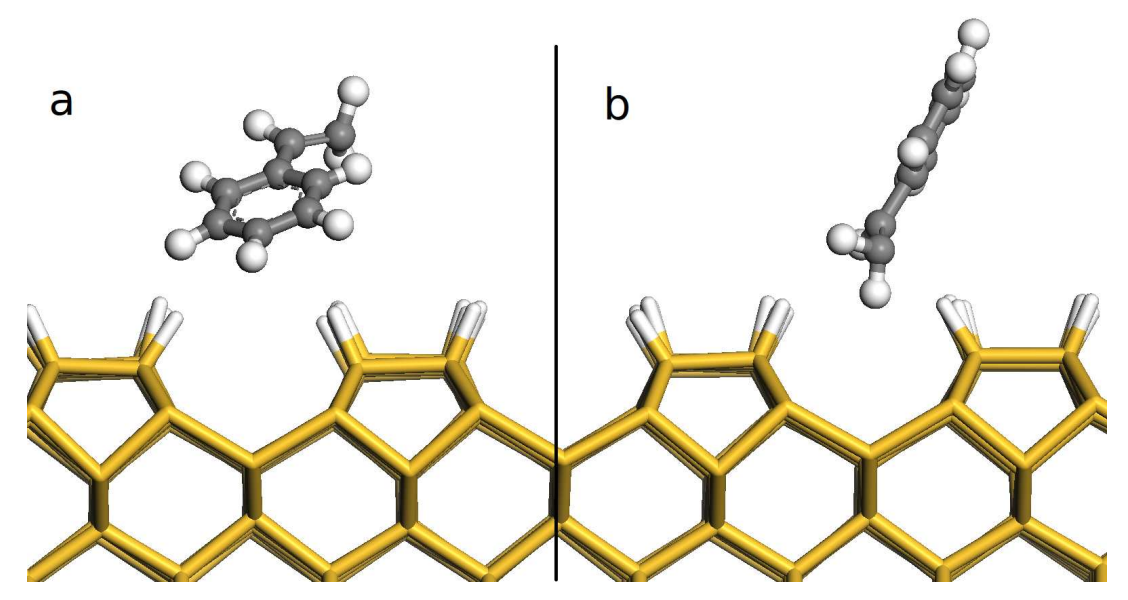

Figura 4.1: Fotografia de duas conformações correspondentes a 20 ps de simulação de Dinâmica Molecular de Impacto para uma molécula de estireno sobre a superfície $\mathrm{Si}(100)(2 \mathrm{x} 1): \mathrm{H}$ utilizando o UFFN.

Para o UFF, a situação é diferente: há atração entre a molécula e os dímeros de superfície. Selecionamos fotografias para duas conformações, $c$ e $d$ (Figura 4.2), na qual se evidencia as situações fisissorvidas comumente obtidas com o UFF. As fotografias referem-se à configurações atômicas decorridos 20 ps de simulação. É possível identificar uma tendência de "acomodação" preferencial sobre a região dos dímeros. Salientamos que, para todas as situações, e para condições de simulação idênticas à aquelas realizadas com UFFN, a atração pela fileira de dímeros se confirma. Outra característica bastante peculiar relativa aos resultados obtidos com o UFF, é o fato de a molécula ter preferência em interagir com a superfície monohidrogenada sempre na configuração horizontal (Figura 4.2, $c$ e $d$ ). Também aqui, a menor distância entre os carbonos do orgânico e os átomos de silício são próximas de $4 \AA$.

Um ponto importante a ser lembrado é que diferentemente de UFFN, no UFF não incluímos interação eletrostática. A atração da molécula de estireno pela região de vale identificada nos cálculos utilizando UFFN pode ser consequência da atração eletrostática entre os hidrogênios negativos da superfície e hidrogênios positivos da molécula (tabela 3.4). Uma situação semelhante foi identificada na interação entre 


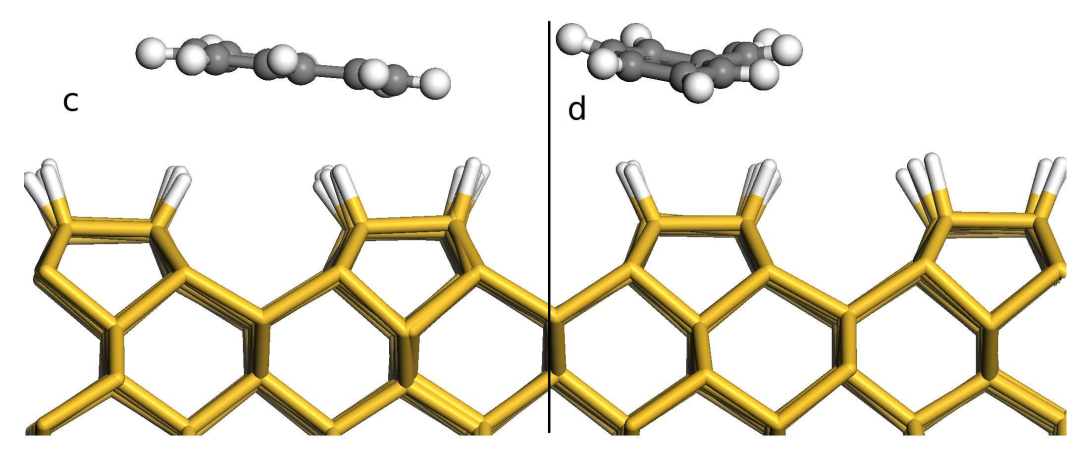

Figura 4.2: Dinâmica Molecular de Impacto para a molécula de estireno sobre a superfície $\operatorname{Si}(100)(2 x 1)$ :H utilizando o UFF. As conformações mostradas representam duas configurações finais da simulação.

a molécula de água e esta mesma superfície [6,55]. Naquele sistema, os hidrogênios positivos da molécula eram atraídos pelos hidrogênios negativos de superfície.

Passemos agora às analises de DMI para uma condição de maior cobertura da superfície. Neste caso, fizemos a deposição de até 12 moléculas de estireno sobre a $\operatorname{Si}(100)(2 \times 1): H$, utilizando os campos UFFN e UFF (com carga nula). A supercélula empregada nas simulações também foi a 8x6. Isto implica que na situação em que existiam 12 moléculas sobre a superfície, tínhamos 1 molécula a cada dois grupos H-Si-Si-H. As moléculas de estireno foram depositadas uma a uma e nas mesmas condições utilizadas para DMI de uma única molécula, já descritas anteriormente.

Nas Figuras 4.3(a), 4.3(b), 4.3(c) e 4.3(d), apresentamos as fotografias para $\mathrm{t}=20$ ps e para diferentes estágios de cobertura da $\mathrm{Si}(100)(2 \mathrm{x} 1): H$. Os resultados se referem a simulações com o campo de força UFFN. Observamos que as moléculas têm tendência à formação de aglomerados durante a interação com a superfície. Este comportamento é particularmente claro na Figura 4.3(d), quando estamos em regime de alta cobertura. Ao longo da simulação, quando as moléculas se aproximam, a interação tende a mantê-las unidas, de modo que seguem praticamente aos grupos ao longo dos 20 ps de simulação. Notemos que a interação preferencial pela regiões de vale persiste, mesmo para o regime de alto fluxo (Figura 4.4(a)). Para as simulações com o UFF, a preferência pela região de dímeros é mantida. No entanto, 


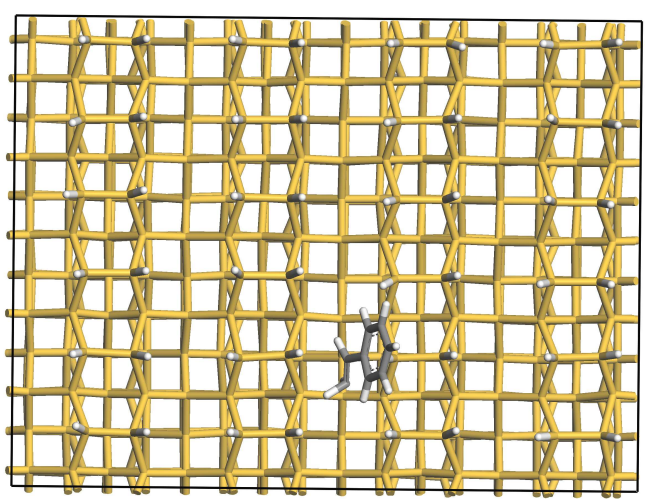

(a) 1 molécula

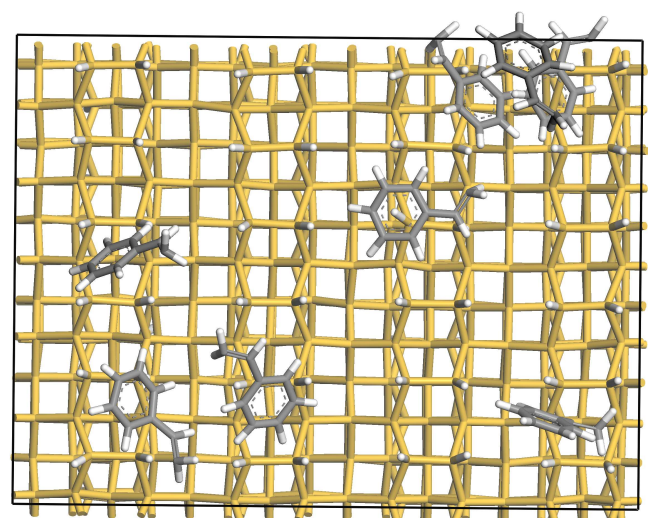

(c) 8 moléculas

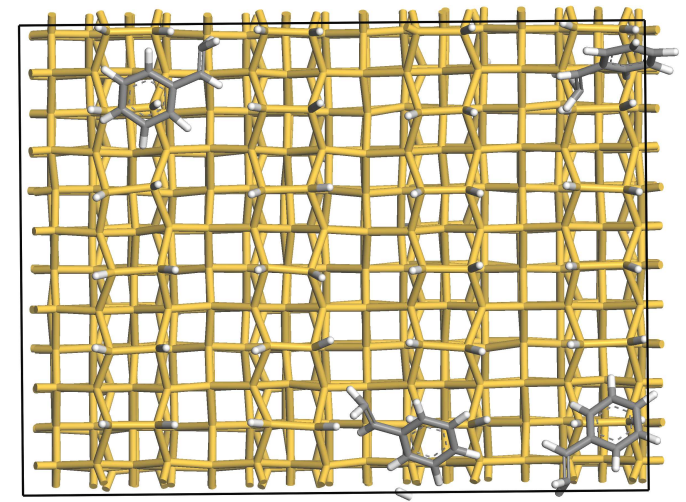

(b) 4 moléculas

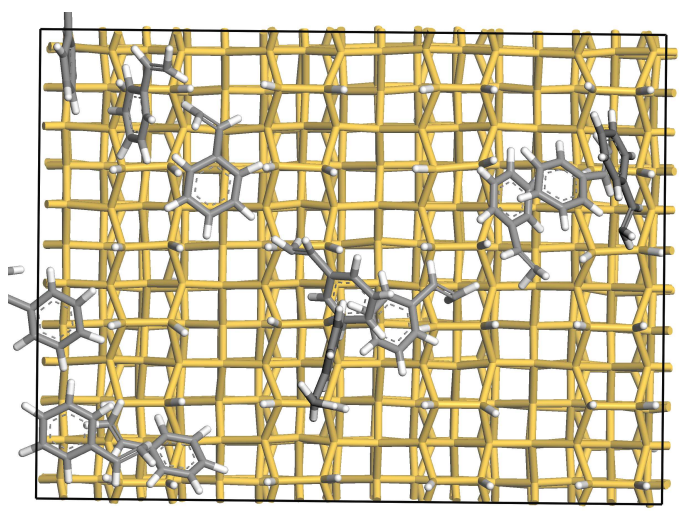

(d) 12 moléculas

Figura 4.3: Fotografias para a fisissorção de moléculas de estireno, em diferentes regimes de cobertura, para $\mathrm{t}=20 \mathrm{ps}$. Resultados obtidos com o UFFN.

para este campo a distruibuição das moléculas sobre a superfície é mais uniforme, conforme ilustrado na Figura 4.4(b). Ou seja, os aglomerados moleculares, observados durante boa parte da simulação com UFFN possuem interação fraca quando utilizamos UFF. Conforme já discutido estes resultados permitem-nos constatar a influência da carga nas interações entre as moléculas, e entre estas e a superfície. Assim como já discutido para o regime de baixo fluxo (1 molécula de estireno sobre a superfície), as distâncias médias dos carbonos em relação aos silícios da superfície, no regime de cobertura máxima (12 moléculas) encontra-se em torno de 4 A. Este resultado foi obtido para ambos os campos de força (UFFN e UFF). 


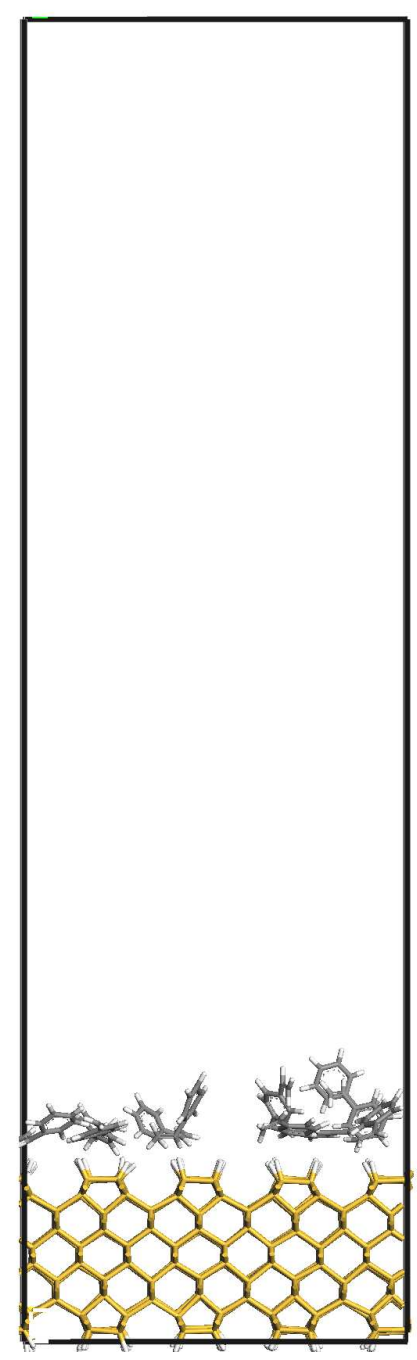

(a) UFFN

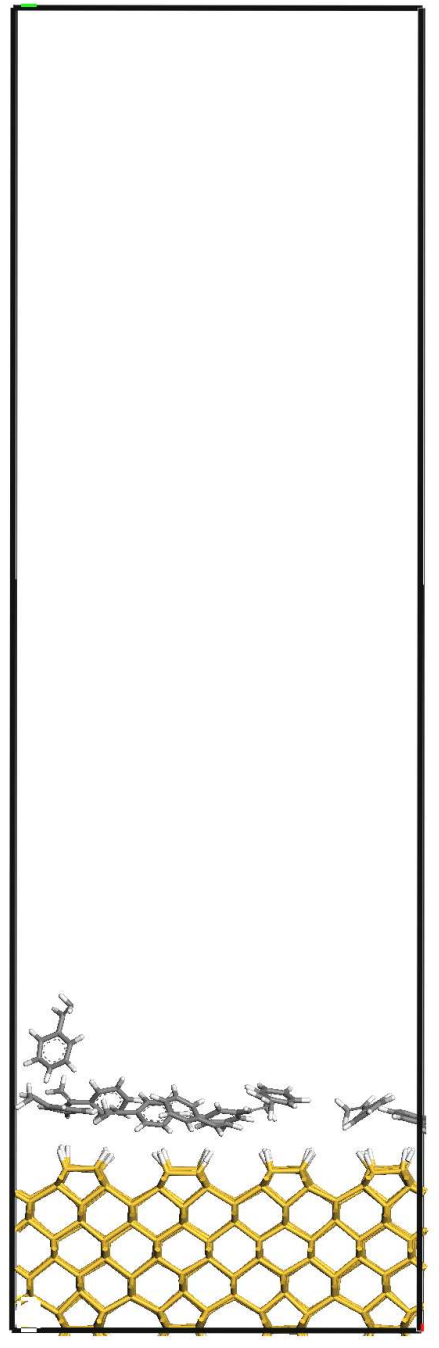

(b) UFF

Figura 4.4: Fotografias para a fisissorção de 12 moléculas de estireno, em diferentes regimes de cobertura, para $\mathrm{t}=20$ ps. Resultados obtidos com o UFFN e UFF, respectivamente. Em (a), notamos a formação de aglomerados de moléculas sobre as regiões de vale da superfície. Em (b), a distrubuição de moléculas é mais uniforme.

\subsection{Moléculas de Estireno Quimissorvidas}

Nesta seção analisamos o comportamento da molécula de estireno após quimissorção sobre a superfície. Pretendemos estudar atomisticamente a conformação molecular das linhas de estireno que resultam do processo de "automontagem" (self-assembling) 
nas superfícies de Si monohidrogenadas, e que tem sido investigado experimentalmente [17]. Trabalhamos com campos de força não reativos, e portanto não podemos simular o processo de automontagem das linhas. Iniciamos pela análise do comportamento de uma única molécula de estireno quimissorvida sobre a superfície $\mathrm{Si}(100)(2 \mathrm{x} 1): \mathrm{H}$, formando uma ligação $\mathrm{Si}-\mathrm{C}$ com o grupo vinil. Antes da quimissorção, o átomo de Si ligado ao orgânico estava originalmente hidrogenado (grupo Si-H que formam os dímeros pristinos). A fatia de $\mathrm{Si}(100)(2 \times 1)$ :H é a mesma empregada no estudo da fisissorção e somente os parâmetros de rede são mantidos fixos durante os cálculos.

Durante as otimizações de geometria, notamos a existência de três possíveis conformações de mínima energia, mostradas na Figura 4.5. Os valores da variação de energia total, relativos à mecânica molecular (em $\mathrm{T}=0 \mathrm{~K})$, para cada campo de força (UFF, PCFF e UFFN), estão listados na tabela 4.1. Calculando-se a diferença entre
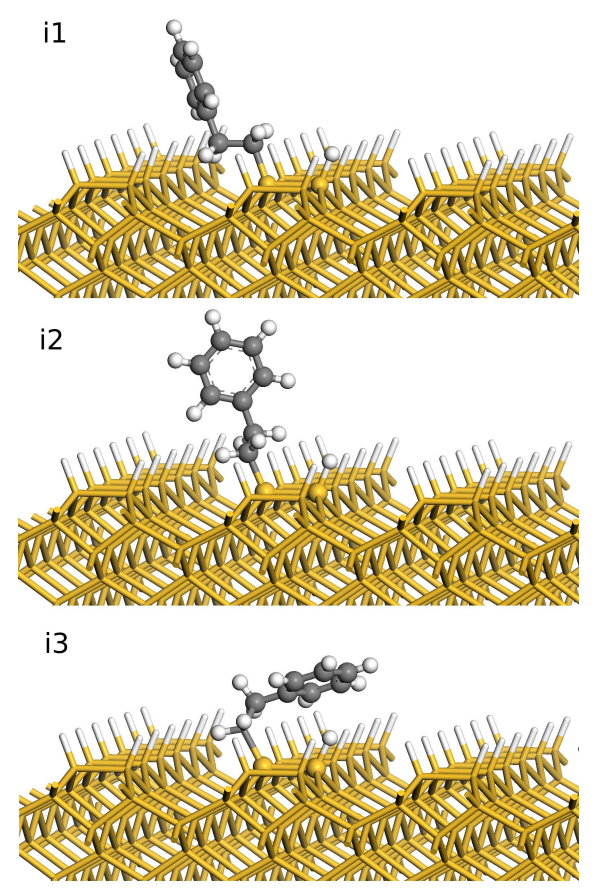

Figura 4.5: Molécula de estireno isolada quimissorvida sobre a $\mathrm{Si}(100)(2 \mathrm{x} 1): \mathrm{H}$ nas três conformações de menores energias. 
a energia obtida com o campo para cada estrutura e a energia da estrutura mais estável para cada um dos campos obtemos as diferenças de energia mostradas na tabela. Lembramos que nas otimizações realizadas com UFF utilizamos carga nula enquanto no PCFF as cargas foram atribuídas pelo próprio campo. Para os três campos utilizados no estudo da quimissorção (UFFN, UFF e PCFF), na configuração mais estável, o grupo fenil tende a permanecer na região de vale da superfície (estrutura i1, Figura 4.5). Para o UFFN, a estrutura i1 é indiscutivelmente a mais estável possuindo diferenças de energia bem definidas. Entretanto, os valores de $\triangle \mathrm{E}$ ( $\mathrm{kcal} / \mathrm{mol})$, tabela 4.1, apontam que a estabilidade das estruturas $i 1$, i2 e $i 3$ é praticamente a mesma para o UFF e PCFF. Com o intuito de investigar, de forma mais adequada, os mínimos de energia para este processo de qumissorção, fizemos um estudo de dinâmica molecular com "annealing", tendo como configurações iniciais as estruturas i1, i2 e i3. Foram simulados 20 ps de dinâmica, com o ensemble NVT, com os ciclos de DMC realizados em $\mathrm{T}=300 \mathrm{~K}$ e passos de $0,001 \mathrm{ps}$.

As diferenças de energia obtidas após os processos de "annealing" (etiquetados por $\mathrm{T}=300 \mathrm{~K}$ ), também foram listadas na tabela 4.1 e referem-se à energia média calculada no último 0,5 ps de simulação, após o sistema ter adquirido equilíbrio termodinâmico. Para as energias obtidas a $300 \mathrm{~K}$, também mostramos na tabela o desvio médio padrão (DMP). A ordem de estabilidade para as estruturas i1, i2 e i3, obtidas com os campos de força padrão UFF e PCFF se invertem. Para o PCFF as três estruturas ainda permanecem praticamente degeneradas em energia, enquanto o resultado obtido com o campo UFF agora prediz que a estrutura mais estável é a i2, e a estrutura i1 é identificada como energeticamente instável. Apenas o UFFN mantém a mesma ordem de estabilidade nos cálculos de otimização de geometria.

Passemos agora à discussão das geometrias que foram visitadas pelo sistema durante o procedimento de DMC com UFFN. Uma confirmação de que a molécula na estrutura $i 1$ realmente está em uma região de estabilidade pode ser obtida quando analisamos os valores da distância interatômica entre o átomo de carbono do grupo fenil (C581) e um átomo de hidrogênio (HS46) do dímero pristino pertencente à 
Tabela 4.1: Energias por célula unitária da molécula de estireno quimissorvida sobre $\operatorname{Si}(100)(2 \times 1)$ :H nas conformações mostradas na Figura 4.5. As energias foram ordenadas em relação à estrutura mais estável, definida como $0 \mathrm{kcal} / \mathrm{mol}$. A T=300 K, mostramos as diferenças de energia média e o desvio médio padrão (DMP) calculados no último 0,5 ps de simulação, após o sistema ter atingido o equilíbrio térmico. Para o UFF, as energias médias totais são de $\approx 800 \mathrm{kcal} / \mathrm{mol}$, enquanto para o $\mathrm{PCFF}$ e UFFN de $\approx 500 \mathrm{kcal} / \mathrm{mol}$.

\begin{tabular}{l|cc|cc}
\hline \hline & & $\mathrm{T}=0 \mathrm{~K}$ & $\mathrm{~T}=300 \mathrm{~K}$ & $\mathrm{DMP}$ \\
Campo & Sistemas & $\Delta \mathrm{E}(\mathrm{kcal} / \mathrm{mol})$ & $\Delta \mathrm{E}(\mathrm{kcal} / \mathrm{mol})$ & $(\mathrm{kcal} / \mathrm{mol})$ \\
\hline \multirow{3}{*}{ UFF } & $\mathrm{i} 1$ & 0,00 & 1,19 & 21,94 \\
& $\mathrm{i} 2$ & 0,24 & 0,00 & 31,27 \\
& $\mathrm{i} 3$ & 1,03 & 0,31 & 25,81 \\
\hline \multirow{3}{*}{ PCFF } & $\mathrm{i} 1$ & 0,00 & 0,00 & 46,86 \\
& $\mathrm{i} 2$ & 0,41 & 7,88 & 23,04 \\
& $\mathrm{i} 3$ & 1,28 & 6,19 & 38,16 \\
\hline \multirow{3}{*}{ UFFN } & $\mathrm{i} 1$ & 0,00 & 0,00 & 42,13 \\
& $\mathrm{i} 2$ & 2,82 & 6,67 & 26,88 \\
& $\mathrm{i} 3$ & 6,40 & 10,10 & 36,82 \\
\hline \hline
\end{tabular}

fileira de dímeros vizinha da molécula de estireno ao longo da dinâmica (Figura 4.6). O comportamento oscilatório dos valores desta distância interatômica evidencia que a molécula tende a permanecer confinada na região de vale. A atração do orgânico por esta região é forte e, mesmo que exista a possibilidade de se visitar outras regiões da superfície, a molécula permanece virtualmente na mesma conformação durante todo o intervalo de tempo investigado. Esta tendência não é observada para as simulações que tiveram como ponto inicial as estruturas $i 2$ e $i 3$, conforme vemos nas Figuras 4.7 e 4.8, respectivamente. Em ambos os casos, a molécula de estireno tende 


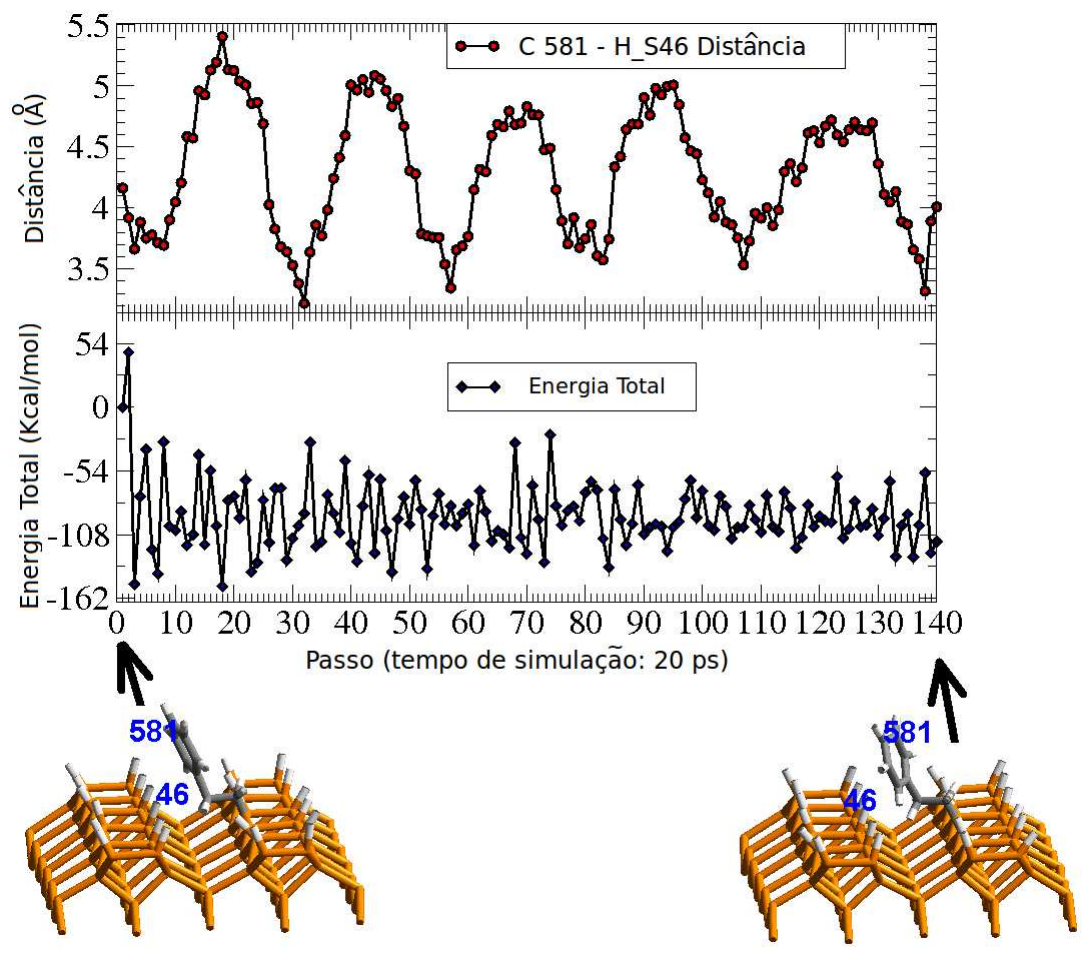

Figura 4.6: Distâncias e energias em função do número de passos de simulação com UFFN. Os gráficos foram obtidos para a conformação $i 1$ da Figura 4.5. Os tipos atômicos envolvidos são os que aparecem na legenda: um carbono do anel aromático da molécula (C 581) e um hidrogênio de superfície (H_S46).

a se aproximar da região de vale, isto é, geometria da estrutura i1. Mudanças mais significativas são observadas na Figura 4.8, onde graficamos os valores da distância entre o átomo de carbono do grupo fenil (C576) e um átomo de silício (Si188) vizinho da ligação Si-C. Para t=0 ps, o grupo fenil está "deitado"sobre a fileira de dímeros, mas decorrido o tempo total de simulação, a molécula encontra-se com este grupo afastado da superfície. Basicamente, isto ocorre devido ao delicado equilíbrio de atração e a repulsão entre carbonos do orgânico e hidrogênios pertencentes à superfície. Em conjunto, estas constatações demonstram que para o UFFN, temos uma região de mínima energia bem caracterizada.

O crescimento de linhas de estireno sobre a superfície monohidrogenada se dá através do processo de automontagem [17]. Em geral, não temos uma única molécula 


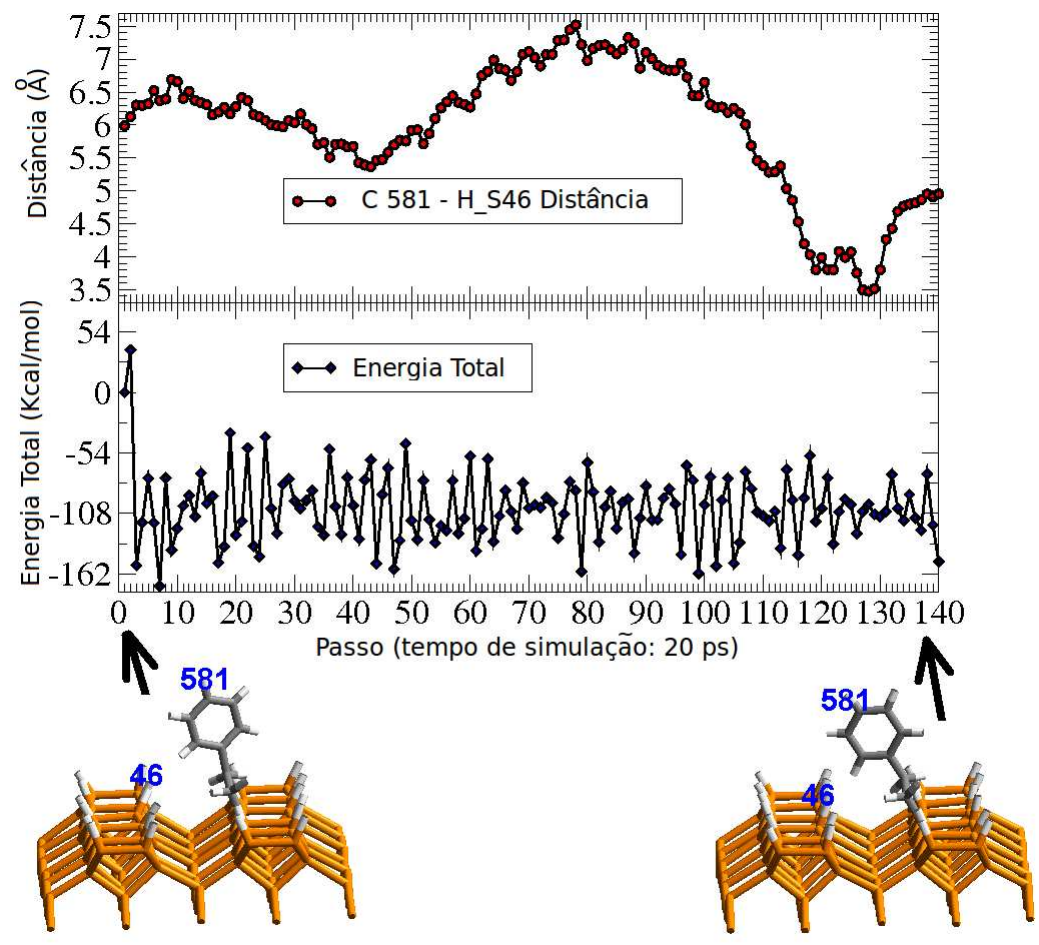

Figura 4.7: Distâncias e energias em função do número de passos de simulação com UFFN. Os gráficos foram obtidos para a conformação i2 da Figura 4.5. Os tipos atômicos envolvidos são os que aparecem na legenda: um carbono do anel aromático da molécula (C 581) e um hidrogênio de superfície (H_S46).

ligada a um átomo da superfície, mas sim várias ligações do tipo Si-C. Já estabelecemos a configuração de menor energia para uma molécula de estireno quimissorvida sobre o semicondutor, passaremos a discutir o comportamento dos fios de estireno sobre $\operatorname{Si}(100)(2 x 1): H$. Também aqui, a metodologia utilizada foi simulação de DMC com a supercélula 8x6, com os campos de força UFF (carga nula) e UFFN. As simulações tiveram como ponto inicial 5 conformações distintas (Figura 4.9) obtidas a partir da quimissorção de 6 moléculas de estireno, através da ligação Si-C, ocupando totalmente uma fileira de dímeros. A ligação Si-C ao longo da fileira é sobre átomos equivalentes de Si ao longo da fileira de dímeros, a única diferença entre as configurações é o posicionamento relativo dos grupos fenil (Figura 4.9), o que altera as conformações seja das moléculas, seja suas posições relativas. 


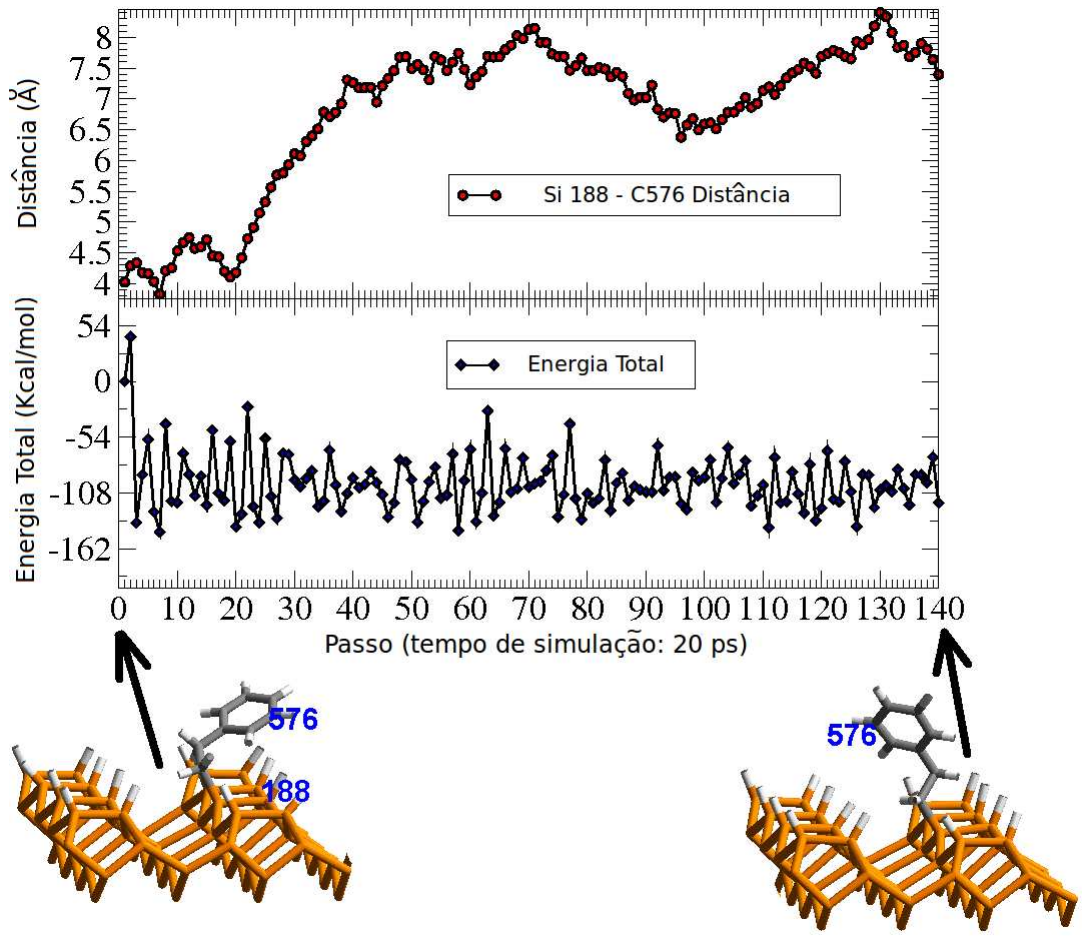

Figura 4.8: Distâncias e energias em função do número de passos de simulação com UFFN. Os gráficos foram obtidos para a conformação 3 da Figura 4.5. Os tipos atômicos envolvidos são os que aparecem na legenda: um silício de superfície (Si 188) e um carbono do anel aromático da molécula (C 576).

Aqui iniciamos o cálculo otimizando estruturas diferentes, a $0 \mathrm{~K}$, em seguida submetidas ao processo de "annealing". As diferenças de energia obtidas após os processos de "annealing" (etiquetados por $\mathrm{T}=300 \mathrm{~K}$ ) foram listadas na tabela $4.2 \mathrm{e}$ referem-se à energia média calculada no último 0,5 ps de simulação, após o sistema ter adquirido equilíbrio. A estrutura mais estável foi escolhida para definir nosso zero de energia. Novamente mostramos na tabela o desvio médio padrão (DMP). Para ambos os campos de força a estrutura 1, na qual as moléculas de estireno estão com os grupos fenil posicionados em espinha de peixe, é energeticamente favorável (Figura 4.9, tabela 4.2). No entanto, o resultado UFFN para a estrutura 3, em que as moléculas encontram-se posicionadas sobre a região de vale (ordenamento tipo pilha- $\pi$ ) mostra energia muito próxima à da estrutura 1. Para as demais estruturas, 


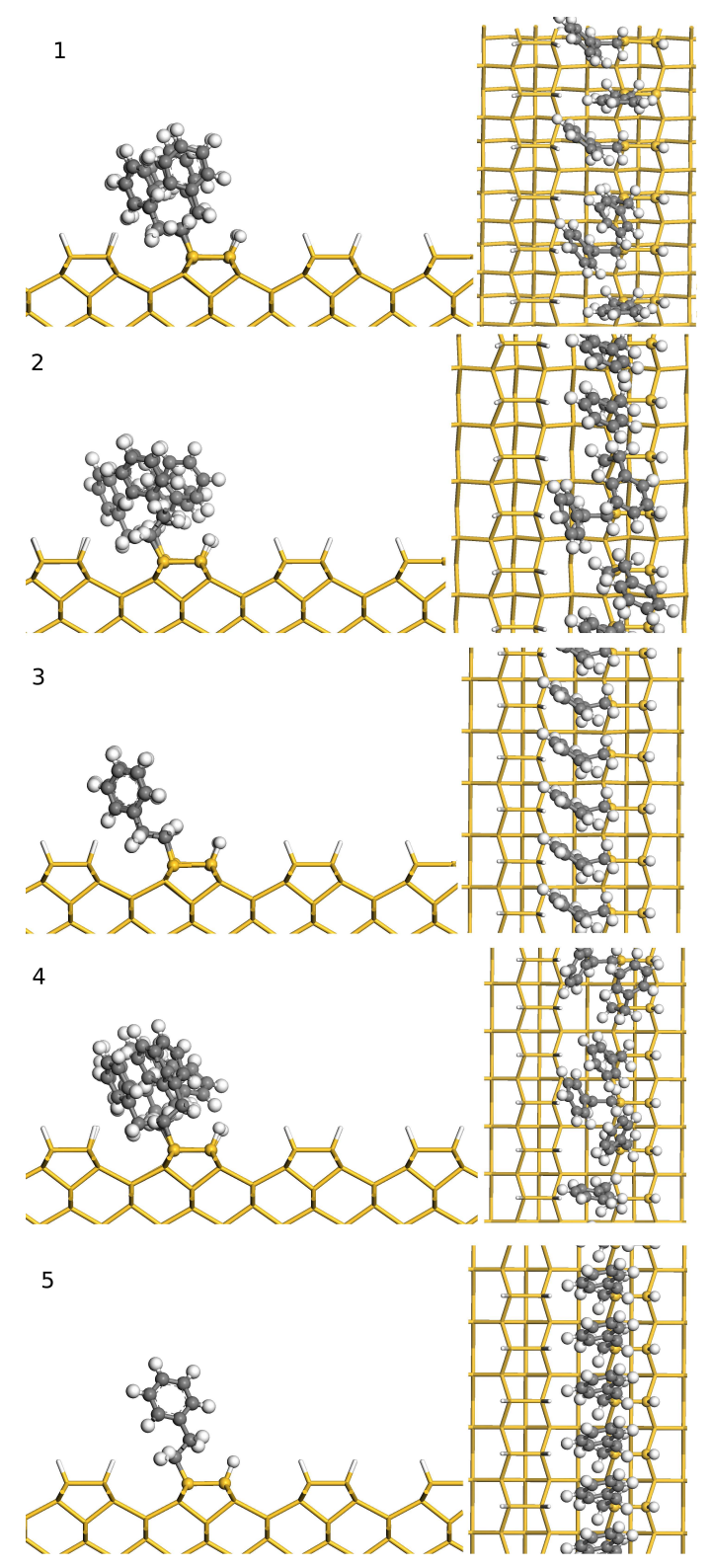

Figura 4.9: Linhas de estireno quimissorvidas em diferentes conformações iniciais sobre a superfície $\operatorname{Si}(100)(2 x 1): H$ utilizando uma célula unitária (8x6).

a ordem de estabilidade utilizando UFF e UFFN são também diferentes. Podemos para os resultados UFFN sintetizar como segue: na conformação 3 todos os grupos fenil estão posicionados sobre a região de vale e a interação entre molécula e superfície é mais forte; já na conformação 5 todas as moléculas estão na posição "em pé", como 
Tabela 4.2: Energias médias por célula unitária (8x6) e DMP das linhas de estireno para as conformações mostradas na Figura 4.9. As energias médias em relação à estrutura mais estável, definida como $0 \mathrm{kcal} / \mathrm{mol}$ foram obtidas durante o último 0,5 ps de simulação, após o sistema ter adquirido equilíbrio. Para o UFFN, as energias médias totais são de $\approx 1700 \mathrm{kcal} / \mathrm{mol}$, enquanto para UFF de $\approx 1000 \mathrm{kcal} / \mathrm{mol}$.

\begin{tabular}{c|ccc}
\hline \hline & & $\mathrm{T}=300 \mathrm{~K}$ & $\mathrm{DMP}$ \\
campo & sistemas & $\triangle \mathrm{E}(\mathrm{kcal} / \mathrm{mol})$ & $(\mathrm{kcal} / \mathrm{mol})$ \\
\hline & 1 & 0,00 & 20,07 \\
& 2 & 24,70 & 24,12 \\
UFF & 3 & 25,86 & 29,93 \\
& 4 & 28,08 & 40,96 \\
& 5 & 43,35 & 18,75 \\
\hline \multirow{4}{*}{ UFFN } & 1 & 0,00 & 17,57 \\
& 2 & 8,14 & 12,88 \\
& 3 & 0,48 & 28,37 \\
& 5 & 21,15 & 27,53 \\
\hline \hline
\end{tabular}

o grupo fenil distante da superfície, e finalmente na conformação 1 uma molécula está no vale e suas vizinhas no dímero. Em temperatura, a diferença de estabilidade entre todas as moléculas no vale, e esta última configuração, é desprezível. A estrutura 4, a mais desordenada, é improvável já que sua energia já está próxima ao DMP da estrutura mais estável.

Para verficarmos qual dentre as possíveis estruturas de mínimo obtidas com UFFN é a de menor energia simulamos adicionalmente três sistemas, obtidos a partir das estruturas 1, 3 e 5, mas agora com o maior grau possível de ordenamento. Para a estrutura 1, construímos uma célula unitária 4x2, com duas moléculas quimissorvi- 


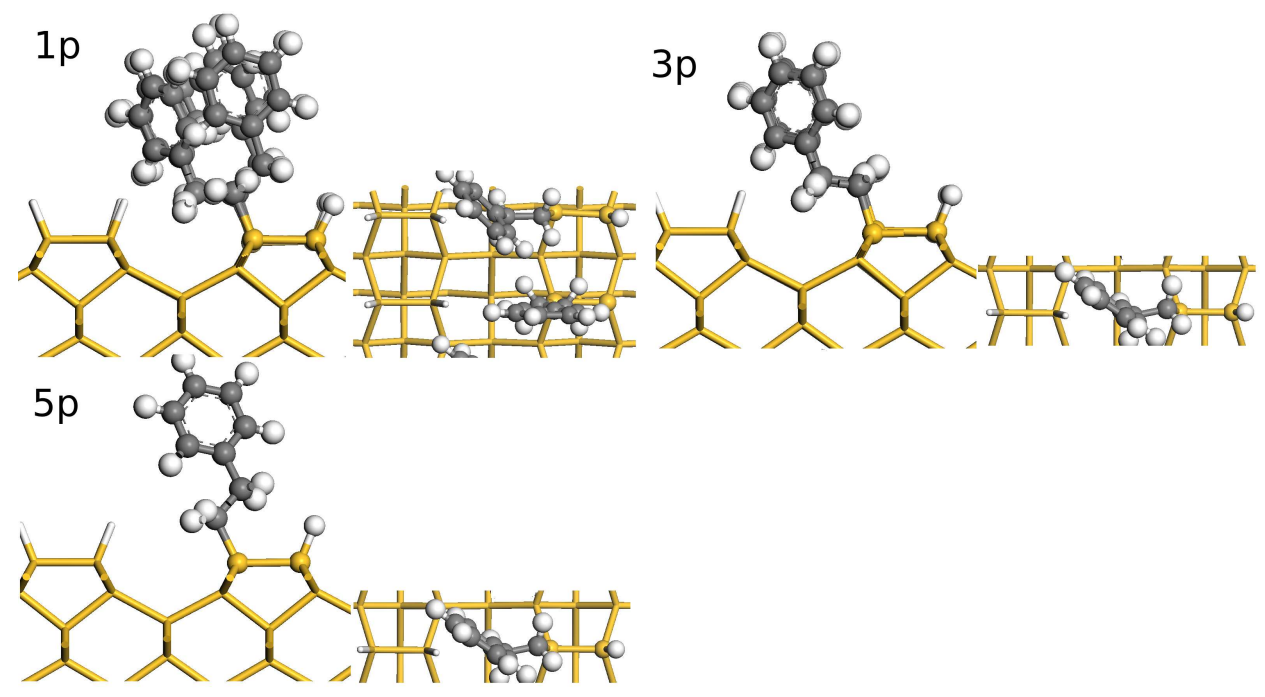

Figura 4.10: Linhas de estireno obtidas das estruturas 1, 3 e 5 (Figura 4.9). Para simular o sistema periódico obtivemos três diferentes conformações da molécula sobre a superfície $\operatorname{Si}(100)(2 \mathrm{x} 1): H$. Utilizamos uma célula unitária (4x1) para simular as linhas tipo pilha- $\pi$ mostradas nas estruturas 3 e 5 . Para estrutura com ordenamento tipo espinha de peixe, estrutura 1, utilizamos uma célula (4x2) para representar moléculas sobre a região de vale e suas vizinhas no dímero da superfície.

das em espinha de peixe, e para as estruturas obtidas de 3 e 5 (pilha- $\pi$ ) reduzimos à célula unitária 4x1 (Figura 4.9). As três estruturas estão mostradas na Figura 4.10. A periodicidade nas direções $x$ e $y$ garante a simulação das linhas ordenadas, e na direção z continuamos empregando 100 Å. Realizamos otimização de geometria pelo UFFN mantendo os parâmetros de rede fixos. Na tabela 4.3, listamos as diferenças de energia total $(\triangle \mathrm{E})$ por célula $4 \mathrm{x} 2$ e novamente a estrutura de menor energia foi definida como nosso zero de energia. Vemos uma alteração no ordenamento, pois a estrutura de menor energia é novamente aquela em que todas as moléculas estão sobre a região de vale (conformação $3 p$ ). A linha com moléculas sobre os dímeros (conformação $5 p$ ) é menos favorável energeticamente, enquanto a que coloca uma molécula sobre o vale e suas vizinhas no dímero (conformação $1 p$ ) apresenta agora comportamento intermediário. Listamos também as diferenças de energia associadas 
Tabela 4.3: Energia por célula (4x2) das linhas de estireno para as conformações periódicas mostradas na Figura 4.10 (ver texto). As energias foram ordenadas em relação à estrutura mais estável, definida como $0 \mathrm{kcal} / \mathrm{mol}$, inclusive aquelas para termos específicos, vdW e ligados.

\begin{tabular}{l|ccc}
\hline \hline sistemas & $\Delta \mathrm{E}(\mathrm{kcal} / \mathrm{mol})$ & $\Delta \mathrm{E}_{v d W}(\mathrm{kcal} / \mathrm{mol})$ & $\Delta \mathrm{E}_{\text {ligados }}(\mathrm{kcal} / \mathrm{mol})$ \\
\hline $1 \mathrm{p}$ & 1,27 & 3,40 & $-2,20$ \\
$3 \mathrm{p}$ & 0,00 & 0,00 & 0,00 \\
$5 \mathrm{p}$ & 2,60 & 2,15 & 0,10 \\
\hline \hline
\end{tabular}

a termos ligados $\left(\triangle \mathrm{E}_{\text {ligados }}\right.$, seção 2.1.1) e de vdW $\left(\triangle \mathrm{E}_{v d W}\right)$ em relação à estrutura mais estável. A energia resultante da interação coulombiana é desprezível frente às demais. Ao compararmos as diferenças de energias dos termos ligados e de vdW nas conformações $3 p$ e $1 p$, notamos que existe um balanço em que os termos ligados (repulsivos), que favoreceriam a configuração espinha de peixe, são superados por uma maior energia estabilizante (negativa) de vdW na configuração $3 p$, pilha- $\pi$ sobre o vale.

Novamente as diferenças de energia não são altas o suficiente para que possamos afirmar que o ordenamento aparente nos experimentos de STM seja oriundo da estabilidade estrutural de uma corformação específica.

Reforçamos também que, no estudo de dinâmica, não observamos a passagem do sistema de uma estrutura a outra sequer quando alcançamos a temperatura a 600K.

Desta forma, levantamos a possibilidade de que o ordenamento já estabelecido no processo de formação da linha, seja ditado pela cinética da reação em cadeia. 


\section{Capítulo 5}

\section{Sumário e Conclusões}

Este trabalho teve como objetivo investigar a conformação de linhas de estireno sobre a superfície de $\operatorname{Si}(100)(2 x 1): H$, utilizando Dinâmica Molecular Clássica. Existem diversos conjuntos de parâmetros ou campos de força, e optamos pelo campo editável (aberto) Universal Force Field (UFF) que apresenta resultados razoáveis para certos parâmetros de sistemas orgânicos, mas não para todas as estruturas utilizadas neste trabalho, seja comparados a cálculos ab initio, ou experimentais. Obtivemos novos parâmetros ligados para o UFF no caso do Si, baseados em dados DFT, e com isso foi possível obter excelente descrição estrutural para o cristal de Si, superfície $\operatorname{Si}(100)(2 x 1): H$ e mesmo outras superfícies. Tanto para o Si quanto para a molécula reparametrizamos os termos de interação não ligados.

Utilizando nosso campo (UFFN) simulamos diferentes situações, com moléculas de estireno fisissorvidas e quimissorvidas sobre a $\operatorname{Si}(100)(2 \mathrm{x} 1): \mathrm{H}$.

A análise de nossos resultados para a deposição de fluxo de moléculas de estireno sobre a $\operatorname{Si}(100)(2 \times 1): H$ indica a formação de agregados de moléculas de estireno sobre as regiões de vale da superfície. Para as simulações de chegada da primeira molécula, notamos maior interação entre o anel aromático da molécula e o vale da superfície, e também entre o grupo vinil da molécula e os dímeros pristinos.

Passando ao caso de uma molécula isolada quimissorvida, identificamos como estrutura de mínimo de energia aquela em que o anel aromático tende a permanecer 
sobre a região de vale da superfície, entretanto outras conformações tem energia muito próxima, principalmente se considerarmos situações de temperatura ambiente.

Quanto à estrutura de linhas de estireno, nossos resultados indicam que a interação de van der Waals é dominante, e que a configuração mais estável tem todas as moléculas na região de vale em um ordenamento tipo "pilha- $\pi$ ". A estrutura com ordenamento tipo "espinha de peixe" mostra comportamento intermediário em relação às duas estruturas tipo "pilha- $\pi$ " (sobre o vale e sobre o dímero). Novamente aqui nossos resultados mostram energias muito próximas para essas duas conformações, que não justificam em princípio definirmos um ordenamento intermolecular. Assim, concluímos que se existe um ordenamento preferencial será provavelmente ditado pela cinética da reação em cadeia provocada pela existência inicial de uma dangling bond sobre um dímero da superfície. 


\section{Bibliografia}

[1] M. L. Cohen e J. R. Chelikowski. Electronic Structure and Optical Properties of Semiconductors. Springer-Verlag New York, (1988).

[2] G. P. Srivastava. Rep. Prog. Phys. 60, 561 (1997).

[3] P. Kruger e H. Pollmann. Phys. Rev. Lett. 74, 1155 (1995).

[4] R. A. Wolkow. Phys. Rev. Lett. 68, 2636 (1992).

[5] A. W. Munz, Ch. Ziegler e W. Gopel. Phys. Rev. Lett. 74, 2244 (1995).

[6] R. L. de Sousa. Dissociação da molécula de água sobre superfícies de silício: estudo teórico. Tese de doutorado, IFUSP, São Paulo, (2010).

[7] J. Yoshinobu. Prog. Surf. Sci. 77, 37 (2004).

[8] T. Tabata, T. Aruga e Y. Murata. Surf. Sci. Lett. 179 (1987).

[9] L. Andersohn e U. Kohler. Surf. Sci. 284, 77 (1993).

[10] T. Uozumi, Y. Tomiyoshi, N. Suehira, Y. Sugawara e S. Morita. Appl. Surf. Sci. 188, 279 (2002).

[11] R. J. Hamers, R. M. Tromp e J. E. Demuth. Phys. Rev. B 34, 5343 (1986).

[12] J. E. Northrup. Phys. Rev. B 44, 1419 (1991).

[13] A. Calzolari, A. Ruini, E. Molinari e M. J. Caldas. Phys. Rev. B 73, 125420 (2006). 
[14] M. A. Walsh, S. R. Walter, K. H. Bevan, F. M. Geiger e M. C. Hersam. J. Am. Chem. Soc. 132, 3013 (2010).

[15] L. Yang e D. J. Doren. J. Phys. Chem. C 112, 781 (2008).

[16] L. Yang e D. J. Doren. J. Phys. Chem. C 114, 20016 (2010).

[17] G. P. Lopinski, D. D. M. Wayner e R. A. Wolkow. Nature 406, 48 (2000).

[18] J. H. Cho, D. H. Oh e L. Kleinman. Phys. Rev. B 65, 081310 (2002).

[19] R. Basu, N. P. Guisinger, M. E. Greene e M. C. Hersam. Appl. Phys. Lett. 85, 2619 (2004).

[20] S. Seo, L. C. Grabow, M. Mavrikakis, R. J. Hamers, N. J. Thompson e P. G. Evans. Appl. Phys. Lett. 92, 153313 (2008).

[21] J. Kohanoff. Electronic Structure Calculations for Solids and Molecules - Theory and Computational Methods. Cambridge Universtiy Press, (2006).

[22] R. M. Martin. Electronic Structure - Basic Theory and Practical Methods. Cambridge Universtiy Press, (2004).

[23] L. Verlet. Phys. Rev. 159, 98 (1967).

[24] Cerius Version 4.6. Accelrys Inc. Copyright, 2010.

[25] M. J. Hwang, T. P. Stockfish e A. T. Hagler. J. Am. Chem. Soc. 116, 2515 (1994).

[26] A. K. Rappé, C. J. Casewit, K. S. Colwell, W. A. Goddard III e W. M. Skiff. J. Am. Chem. Soc. 114, 10024 (1992).

[27] A. K. Rappé e W. A. Goddard III. J. Phys. Chem. 95, 3358 (1991).

[28] F. L. Hirshfeld. Theor. Chem. Acc. 44, 129 (1977). 
[29] M. Born e J. R. Oppenheimer. Adv. Phys. 84, 457 (1927).

[30] K. Capelle. Braz. Joun. Phys. 36, 1318 (2006).

[31] P. Hohenberg e W. Kohn. Phys. Rev. B 136, 864 (1964).

[32] J. D. M. Vianna, A. Fazzio e S. A. Canuto. Teoria Quântica de Moléculas e Sólidos. Editora Livraria da Física, (2004).

[33] W. Kohn e L.J. Sham. Phys. Rev. A 140, 1133 (1965).

[34] D. M. Ceperley e B. J. Alder. Phys. Rev. Lett. 45, 566 (1980).

[35] J. P. Perdew e A. Zunger. Phys. Rev. B 23, 5048 (1981).

[36] J. P. Perdew, K. Burke e M. Ernzerhorf. Phys. Rev. Lett. 77, 3865 (1996).

[37] J. P. Perdew e Y. Wang. Phys. Rev. B 45, 13244 (1992).

[38] A. Tkatchenko e M. Scheffler. Phys. Rev. Lett. 102, 073005 (2009).

[39] V. Blum, R. Gehrke, F. Hanke, P. Havu, V. Havu, X. Ren, K. Reuter e M. Scheffler. Comput. Phys. Commun. 180, 2175 (2009).

[40] P. Giannozzi et al. J. Phys. Condens. Matter 21, 395502 (2009).

[41] N. Troullier e J. L. Martins. Phys. Rev. B 43, 1993 (1991).

[42] A. M. Rappe, M. Rabe, E. Kaxiras e J. D. Joannopoulos. Phys. Rev. B 41, 1227 (1990).

[43] D. Vanderbilt. Phys. Rev. B 41, 7892 (1990).

[44] V. Havu, V. Blum, P. Havu e M. Scheffler. J. Chem. Phys. 228, 8367 (2009).

[45] N. Marom, A. Tkatchenko, M. Scheffler. e L. Kronik. 6, 81 (2010).

[46] N. Marom, J. Bernstein, J. Garel, A. Tkatchenko, E. Joselevich, L. Kronik e O. Hod. Phys. Rev. Lett. 105, 4 (2010). 
[47] H. J. Monkhorst e J. D. Pack. Phys. Rev. B 13, 5188 (1976).

[48] G. K. Ramachandran et al. J. Phys. Condens. Matter 12, 4013 (2000).

[49] M. A. Santos e M. J. Caldas. Synthetic Metals 159, 2302 (2009).

[50] O. Anatole von Lilienfeld e Alexandre Tkatchenko (unpublished). .

[51] Cheol Ho Choi e Miklos Kertesz. J. Phys. Chem. A 101, 3823 (1997).

[52] J. Ciston, L. D. Marks, R. Feidenhans'l, O. Bunk, G. Falkenberg e E. M. Lauridsen. Phys. Rev. B 74, 085401 (2006).

[53] Mascovic et al. J. Phys. Chem. 16, 6731 (1986).

[54] A. K. Rappé, C. J. Casewit, K. S. Colwell, W. A. Goddard III e W. M. Skiff. J. Am. Chem. Soc. 114, 10024 (1992).

[55] R. L. de Sousa e M. J. Caldas. Phys. Rev. B 84, 205314 (2011). 